\title{
Un testimonio inédito de Vetus Latina (1 Macabeos 1,1-6,40): el Codex Hubertianus (Londres, British Museum, Add 24142), Edición crítica
}

José Manuel CAÑAS REÍlLO

La primera edición de las versiones latinas de 1-2 $\mathrm{Mac}^{1}$ fue llevada a cabo por D. De Bruyne, en colaboración con B. Sodar, en $1932^{2}$. En ella se tuvieron en cuenta todos los testimonios de $V L$ conocidos en aquel momento y los más importantes de Vulg. Desde entonces, numerosos estudios han sacado a la luz nuevos testimonios manuscritos veterolatinos de 1-2 Mac que han contribuido

1 Agradezco al Dr. H. J. Frede (m. en 1998), director del Vetus Latina Institut de Beuron (Alemania), las facilidades que me dio para la consulta de los fondos bibliográficos y de microfilms de ese centro, y el permiso para la consulta de las transcripciones del Palimpsesto de León realizadas por B. Fischer allí conservadas; igualmente le agradezco el envío de fotografías del códice Hubertiano de Londres (British Museum, Add 24142) y del códice de Oxford (Bodleian Library, Laud. Lat. 22), sin las cuales no hubiera sido posible la realización del presente trabajo.

Las abreviaturas y siglas que utilizaré son las siguientes: $B S=$ Biblia Sacra iuxta latinam vulgatam versionem ad codicum fidem (Roma $1926 \mathrm{ss}$.); VL = Vetus Latina; $\mathrm{VL}=$ Vetus Latina: die Reste der altlateinischen Bibel (Friburgo 1949 ss.); $V u l g=$ Vulgata. Para la designación de los manuscritos de $V L$ sigo la numeración de B. FISCHER, Verzeichnis der Sigel für Handschriften und Kirchenschriftsteller, VL 1 (Friburgo 1949), que introduzco con la abreviatura «VL» (cf. la actualización de R. GRYSON, Altlateinische Handschriften / Manuscrits vieux latins: répertoire descriptif, première partie: Mss. 1-275 d'après un manuscrit inachevé de Hermann Josef Frede, VL 1,2 A [Friburgo 1999]); para los de Vulg utilizo las siglas de BS 18.

${ }^{2}$ Les anciennes traductions latines des Machabées, AnMar 4 (Maredsous 1932). 
considerablemente a perfilar el panorama textual trazado por De Bruyne - Sodar ${ }^{3}$.

El objetivo del presente trabajo es la edición crítica de uno de estos nuevos testimonios de 1-2 Mac, que considero de gran importancia para la historia textual de las versiones latinas de esos libros por las razones que más adelante expondré. Se trata del códice Hubertiano (Londres, British Museum, Add 24142), que tiene texto de $V L$ en 1 Mac 1,1-6,40, que designaré con la sigla $\mathrm{H}$. $\mathrm{La}$ existencia de este testimonio veterolatino de $1 \mathrm{Mac}$ fue dada a conocer por B. Fischer en $1965^{4}$. El resto del manuscrito tiene texto de Vulg de tipo teodulfiano, designado en las ediciones modernas con la sigla $\Theta^{\mathrm{H}}$.

Poco conocíamos hasta ahora del texto $\mathrm{H}$, a excepción de algunas lecturas publicadas por los Benedictinos de la Abadía de San Jerónimo de Roma en el aparato crítico de su edición de Vulg ${ }^{5}$. El restante texto de 1-2 Mac y la mayor parte de los restantes libros bíblicos se han cotejado en $B S$ y en la serie de ediciones VL que lleva a cabo el Vetus Latina Institut de Beuron (Alemania) ${ }^{6}$.

${ }^{3}$ Cf. T. Ayuso Marazuela, «La Biblia de Calatayud», Universidad (Zaragoza) 18 (1941) págs. 529-550 (= La Biblia de Calatayud. Un notable códice desconocido [Zaragoza 1941]); G. D. KILPATRICK, «I-III Maccabees», en H. M. ORLINSKY (ed.), Origins, Recensions and Interpretations. Selected Essays with a Prolegomenon by S. Jellicoe (Nueva York 1974) págs. 418-433 (= GGA [1963]); B. FISCHER, «Bibeltext und Bibelreform unter Karl dem Grossen», en B. FISCHER, Lateinische Bibelhandschriften im frühen Mittelalter, AGLB 11 (Friburgo 1985) págs. 101-202 (= Karl der Große, Lebenswerk und Nachleben, hrg. von W. BRAUNFELS, Band II: Das geistige Leben, hrg. von B. BISCHOFF [Düsseldorf 1965] págs. 156-216) pág. 198; B. FISCHER, «Zur Überlieferung altlateinischer Bibeltexte im Mittelalter», en B. FISCHER, Lateinische Bibelhandschriften págs. 404-421 (reimpr. de NAK 56 [1975] págs. 19-33) pág. 418; F. VAtTiONI, «Frammenti Biblici Latini», Augustinianum 15 (1975) págs. 389-422: págs. 394 ss.; H. J. FREDE., «Libri Macchabaeorum veteris latinae versionis», en H. J. FredE, U. FrÖHLICH, H. STANJEK, Vetus LatinaFragmente zum Alten Testament. Die pelagianische Epistula ad quandam matronam christianam, AGLB 28 (Friburgo 1996) págs. 205-229; y mis trabajos Glosas marginales de Vetus Latina en Biblias Vulgatas españolas: 1-2 Macabeos, TECC 65 (Madrid 2000) págs. 43 y 49, y «Fragmentos españoles de la Vulgata de 1-2 Macabeos: el fragmento de Vich y la Biblia de Valvanera; edición y estudio», Sefarad 60 (2000) págs. 19-41.

${ }^{4}$ FISCHER «Bibeltext und Bibelreform» pág. 143.

${ }^{5}$ Libri I-II Macchabeorum, BS 18 (Roma 1995).

${ }^{6}$ El texto de $V u l g$ de $\Theta^{\mathrm{H}}$ ha sido cotejado, entre otras, en las siguientes ediciones: las varias de W. THIELE, Epistulae Catholicae, VL 26/1 (Friburgo 19561969), Sapientia Salomonis, VL 11/1 (Friburgo 1977-) y Sirach (Ecclesiasticus), VL 11/2 (Friburgo 1987-); las de H. J. FredE, Epistula ad Ephesios, VL 24/1 (Friburgo 
El códice Hubertiano tiene 248 folios de 32,5 / 33 x 24 cms., $<26,3 \times 19,5>$ cms., con 3 columnas de 62 líneas, en minúscula carolingia ${ }^{7}$. Probablemente fue copiado en Orleans ${ }^{8}$ entre los años 795 y 800 . En el siglo XVIII, el manuscrito se encontraba en el Monasterio de Sain Hubert en las Ardenas (diócesis de Lieja, Bélgica), como indica una nota del códice. En 1861 fue adquirido por el British Museum ${ }^{9}$. Contiene una Biblia casi completa, a excepción de algunas lagunas al comienzo de Génesis hasta 49,5, en Oseas 6,9 - Malaquías y en las Epístolas Católicas desde $1 \mathrm{Pe}$ dro 4,3 (desideriis); faltan Hechos de los Apóstoles y Apocalipsis.

1 Mac 1,1-6,40 ocupa los folios $184 \mathrm{r}$ (col. $2^{\mathrm{a}}$ ) a $186 \mathrm{r}\left(\mathrm{col} .2^{\mathrm{a}}\right)$. Está encabezado por el prólogo Macchabeorum libri duo praenotant que aparece mayoritariamente en manuscritos de $V u l g{ }^{10}$.

B. Fischer ${ }^{11}$ señaló la estrecha relación del texto $\mathrm{H}$ con el manuscrito Complutense (Madrid, Biblioteca de la Universidad Complutense 31 , VL 109), que pertenece al tipo textual $L$ de D. De Bruyne - B. Sodar. En opinión de estos autores, el mejor representante de $L$ en 1-2 Mac es el manuscrito de Lyon, Bibliothèque

1962-1964) y Epistulae ad Thessalonicenses, Timotheum, Titum, Philemonem, Hebraeos, VL 25,1 (Friburgo 1987); así como en las de E. SCHUlz-FLÜGEL, Canticum Canticorum, VL 10/3 (Friburgo 1992-); U. FRÖHLICH, Epistula ad Corinthios I, VL 22 (Friburgo 1995-); y H. S. EymANN, Epistula ad Romanos, VL 21 (Friburgo 1996-).

7 Para descripciones cf. Catalogue of Additions to the Manuscripts in the British Museum in the years MDCCCLIV-MDCCCLXXV (Londres 1877, 1967²) vol. II $\mathrm{n}^{\circ}$ 24142; S. BERGER, Histoire de la Vulgate pendant les premiers siècles du Moyen Âge (París 1893) (= Hildesheim - Nueva York 1976) pág. 390; F. G. KENYON, Facsimiles of Biblical Manuscripts in the British Museum (Londres 1900) $\mathrm{n}^{\circ} \mathrm{XV}$; H. QUentin, Mémoire sur l'établisement du texte de la Vulgate, I ${ }^{\mathrm{re}}$ partie: Octateuque, CBL 6 (Roma - París 1922) pág. 251, y Liber Genesis, BS 1 (Roma 1926) págs. XXXII-XXXIII; T. AYUSO MARAZUELA, La Vetus Latina Hispana: 1 , Prolegómenos, TECC 1 (Madrid 1953) pág. 362. Cf. también las ediciones más recientes en la serie VL citadas en nota 6.

8 Así piensan KenYon Facsimiles n ${ }^{\circ}$ XV, y B. BISCHOFF, «Frühkarolingische Handschriften und ihre Heimat», Scriptorium 22 (1968) págs. 306-314: pág. 309.

9 Cf. Quentin Mémoire pág. 251.

${ }^{10}$ Estos manuscritos son $\Delta^{\mathrm{L}} \Theta^{\mathrm{SM}} \mathrm{Z}^{\mathrm{A}} \Gamma^{\mathrm{A}} \Psi^{\mathrm{D}} \Omega^{\mathrm{SJ}}$. Sobre este prólogo, cf. S. BERGER, Les préfaces jointes aux livres de la Bible dans les manuscrits de la Vulgate. Mémoire posthume de M. S. Berger extrait des mémoires présentées par divers savants à l'Academie des Inscriptions et Belles-Lettres, $1^{\text {a }}$ serie, tomo XI, II parte (París 1902) pág. 52 ( $\mathrm{n}^{\circ} 189$ ); T. Ayuso MARAZUELA, «Los elementos extrabíblicos de los Macabeos y los apéndices del Antiguo Testamento», EstBíb 7 (1948) págs. 147 166: págs. 156-157. El prólogo está publicado en Libri I-II Macchabeorum pág. 5.

11 «Bibeltext und Bibelreform» pág. 143. 
de la Ville 430 (356) (VL 146). En el ámbito de $L$ presentan una forma textual menos pura que el manuscrito de Lyon el citado Complutense, el manuscrito de París, Bibliothèque Nationale, lat. 11553 (VL 7) y las glosas marginales de $V L$ del manuscrito de Madrid, Biblioteca de la Academia de la Historia, Aemilianensis 3 (VL 95).

La investigación posterior a De Bruyne - Sodar ha dado a conocer otros testimonios del tipo textual $L$. Entre ellos destacan las glosas marginales de $V L$ del incunable Escurialense (Biblioteca del Real Monasterio de El Escorial, 54.V.35 [VL 94]), muy similares a las de VL 95, que fueron copiadas por $\mathrm{H}$. del Castillo en el siglo XVI tomando como modelo la perdida Biblia de Valvanera (siglo X) ${ }^{12}$. Asimismo se ha puesto de manifiesto la importancia que tiene para el conocimiento de este tipo textual el palimpsesto de León, Archivo Capitular 15 (VL 67), semiuncial de la primera mitad del siglo VII, conocido por De Bruyne - Sodar pero no utilizado en su edición ${ }^{13}$.

El texto $\mathrm{H}$ parece compartir una base textual común con los manuscritos 94, 95, 109 y las citas de Lucífero de Cagliari y en menor medida con 7 y 67. Este texto existía ya en el siglo IV, como indican sus coincidencias con Lucífero. Pudo estar en uso en España y probablemente el sur de Francia desde la antigüedad tardía.

En su largo proceso de transmisión $\mathrm{H}$ ha sufrido la influencia de la $V u l g$, como se puede apreciar en numerosos pasajes del capítulo 5 .

La edición del texto $\mathrm{H}$ que presento es la primera de carácter crítico hasta ahora realizada. En ella pretendo remontarme al estadio textual más antiguo posible (probablemente el siglo IV) de la

12 Para la edición crítica de estas glosas, cf. CAÑAs Reíllo Glosas marginales págs. 109-138. Para un estudio general sobre las glosas marginales de $V L$ cf. el reciente trabajo de C. MORANO RODRíGUEZ, «La historia textual de las glosas marginales de Vetus Latina del Codex Gothicus Legionensis», en Codex Biblicus Legionensis. 20 Estudios (León 1999) págs. 281-302.

13 Desde S. Berger se sabía que la parte bíblica del palimpsesto podía contener un texto de $V L$ de 1-2 Mac. De Bruyne - Sodar no pudieron colacionarlo en su edición; cf. Les anciennes pág. XIV: «Il n'y a qu'un témoin connu qui manque dans notre édition, c'est la Bible palimpseste de la cathédrale de Léon en écriture semionciale du VII siècle. Comme écriture c'est le témoin le plus ancien. J'avais espéré que le manuscrit aurait pu être photographié, mais cet espoir a été déçu». Algunas de sus lecturas se han dado a conocer en el aparato crítico de Libri I-II Macchabaeorum. 
recensión que este nos ha transmitido. Como criterio básico de edición, he respetado al máximo las lecturas del códice para preservar en lo posible su idiosincrasia. Este respeto ha sido absoluto en el tratamiento de los nombres propios menos usuales, que son muy abundantes en el capítulo 5. No es extraño encontrar a veces llamativas faltas de copista, que he corregido mediante conjeturas basándome en el texto griego, del que las versiones latinas de 1 Mac son traducción muy literal, y en otros testimonios de estas, especialmente pertenecientes al tipo textual $L$.

El códice presenta múltiples correcciones $\left(\mathrm{H}^{2}\right)$, bajo las cuales es posible a veces leer o al menos conjeturar la lectura original $\left(\mathrm{H}^{*}\right)$. Estas son de dos tipos: a) correcciones ortográficas, y b) correcciones que son producto de la confrontación del texto del códice con otros testimonios.

Respecto a las primeras, he optado por editar las de $\mathrm{H}^{2}$, que intentan solventar evidentes faltas ortográficas que resultan llamativas para cualquier lector. Respecto a las segundas, he preferido casi en todos los casos editar las de $\mathrm{H}^{*}$, puesto que suelen ser representativas de un estadio textual más antiguo, especialmente próximo al tipo textual $L$, mientras que las de $\mathrm{H}^{2}$ suelen corresponder a otros tipos textuales.

El códice no presenta una puntuación coherente. Para hacer el texto legible he seguido la puntuación del tipo textual $L$ de De Bruyne - Sodar. Sigo esta misma edición en la numeración de capítulos y versículos, que en algunos pasajes (especialmente del cap. 1) difiere considerablemente de Vulg. He extendido también el uso de mayúscula en inicial a todos los nombres propios que aparecen en el texto, incluidos los referidos a Dios, a pesar de que el códice no suele presentarla.

He leído el texto del códice sobre fotografías proporcionadas por el Vetus Latina Institut de Beuron ${ }^{14}$.

${ }^{14}$ En el aparato crítico utilizo las siguientes siglas y abreviaturas de testimonios: $\mathrm{H}=$ Codex Hubertianus, Londres, British Museum, Add 24142: códice de la edición; 7 = París, Bibliothèque Nationale lat. 11553 (cf. la ed. de DE BRUYNE SODAR); 67 = León, Archivo Capitular 15 (colación sobre las transcripciones de B. Fischer); $94=$ Glosas marginales de $V L$ : Monasterio de El Escorial 54.V.35 (cf. mi edición Glosas marginales citada en nota 3); 95 = Glosas marginales de $V L$ : Madrid, Biblioteca de la Academia de la Historia, Emilianensis 3 (cf. ibidem); 109 = Madrid, Biblioteca de la Universidad Complutense 31 (cf. la ed. de DE BRUYNE SODAR); 146 = Lyon, Bibliothèque de la Ville 430 (356) (cf. ibidem); $195=$ 


\section{EDICIÓN CRÍTICA}

1.- ${ }^{1}$ Et factum est postquam percussit Alexander Filippi Macedo, qui exiuit de terra Cettim, et percussit Darium regem Persarum et Medorum et regnauit loco eius prius in Graecia. ${ }^{2}$ Et constituit proelia multa, et obtinuit munitiones, et interfecit reges terrae, ${ }^{3}$ et pertransiit usque ad fines terrae, et accepit spolia multitudinis gentium, et siluit terra in conspectu eius. ${ }^{4} \mathrm{Et}$ congregauit uirtutem [exercitus] fortem nimis, et exaltatum est cor eius, et regnauit in regionibus gentium et tyrannis, et facti sunt illi in tributum. ${ }^{5} \mathrm{Et}$ post haec decidit in lectum, et cognouit quia moreretur, ${ }^{6}$ et uocauit pueros suos nobiles qui secum erant nutriti a iuuentute, et diuisit illis regnum suum cum adhuc uiueret, ${ }^{7}$ et regnauit Alexander annos XII et mortuus est. ${ }^{8} \mathrm{Et}$ obtinuerunt pueri eius regnum unusquisque in loco suo, ${ }^{9} \mathrm{et}$ inposuerunt sibi omnes diademata post mortem eius et filii eorum post eos annis multis et multiplicata sunt mala in terra. ${ }^{10} \mathrm{Et}$ exiit ex eis peccatrix radix Antiochus filius Antiochi regis qui fuerat Romae obses, et regnauit in anno centesimo septimo et tricesimo in regno Graecorum. ${ }^{11}$ In diebus

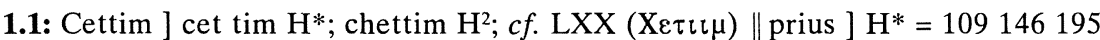

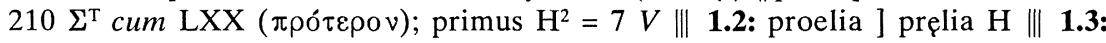

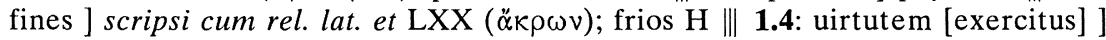
exercitus, probabiliter glossa marginalis $e V$ apud uirtutem in textum introducta; cf. LXX $\left.(\delta \dot{v} v \alpha \mu \imath v) \| \mathrm{et}^{2}\right] \mathrm{H}^{2}=$ rel. lat. cum LXX; om. $\mathrm{H}^{*} \| \mid$ 1.8: obtinuerunt optinuerunt $\mathrm{H} \|$ regnum ] + br. sp. in ras. $\mathrm{H}^{2}$; leg. neq. $\mathrm{H}^{*} \| \mid \mathbf{1 . 1 0}$ : Antiochus ] anthiocus $\mathrm{H} \|$ Antiochi ] anthioci $\mathrm{H}^{*}$; anthiochi $\mathrm{H}^{2} \|$ Romae ] romę $\mathrm{H} \mid \|$

Bolonia, Universidad 2571 (cf. ibidem); $210=$ Oxford, Bodleian Library, Laud. Lat. 22 (colación sobre fotografías); $V=$ Texto de la recensión Vulg según $B S 18$ (cf. esta edición para las siglas de manuscritos de Vulg citados); LXX = edición del texto griego según W. KAPPLER, Maccabaeorum Liber I, Septuaginta: Vetus Testamentum Graecum Auctoritate Academiae Litterarum Gottingensis editum IX/1 (Gotinga 19672); LXX codd = LXX: variantes de manuscritos (cf. el aparato crítico de la citada edición).

Para las citas patrísticas sigo el sistema de abreviaturas y ediciones recomendadas por H. J. FREDE, Kirchenschriftsteller, VL 1/1 (Friburgo 19954). He consultado esas citas en el fichero del Vetus Latina Institut de Beuron (Alemania)

Uso además los siguientes signos, siglas y abreviaturas: $[\ldots]=$ texto que se debe excluir; $\langle\ldots\rangle=$ texto que se debe incluir; $\langle$ curs. $\rangle=$ texto restituido, ilegible en el manuscrito; ] tras una palabra o frase introduce una explicación en el aparato crítico; $\{\ldots\}$ contiene texto corrupto que no se puede corregir mediante conjetura $+=$ adición; * tras las siglas de manuscritos hace referencia a una lectura original, después corregida; 123 tras las siglas de manucritos se refieren a una lectura corregida por un primer copista, un segundo o un tercero; br. $s p$. = breve spatium; del. $=$ delendum $;$ eras.$=$ erasum $;$ hom.$=$ homoeotoleuton; in ras. $=$ in rasura $;$ leg neq. $=$ legi nequit $;$ om. $=$ omittit $;$ rel. lat. $=$ reliqui latini $;$ rest.$=$ restituendum; ut uid $=$ ut uidetur. 
illis exierunt ex Israhel filii iniquii et suaserunt multos dicentes: Eamus et disponamus testamentum cum gentibus quae circum nos sunt, quia ex qua recessimus ab eis inuenerunt nos mala multa. ${ }^{12} \mathrm{Et}$ bonus uisus est sermo in oculis eorum, ${ }^{13} \mathrm{et}$ destinauerunt aliqui ex populo et abierunt ad regem, et dedit illis potestatem ut facerent iustitias gentium. ${ }^{14} \mathrm{Et}$ aedificauerunt gymnasium Hierosolimis secundum legitima nationum, ${ }^{15} \mathrm{et}$ fecerunt sibi praeputia, et recesserunt a testamento sancto, et iuncti sunt nationibus, et uenundati sunt ut facerent malum. ${ }^{16} \mathrm{Et}$ paratum est regnum in conspectu Antiochi et coepit regnare in terra Aegypti ut regnaret super duo regna. ${ }^{17} \mathrm{Et}$ intrauit in Aegyptum in turba graui, in curribus et elefantis et copiosa nimium multitudine. ${ }^{18} \mathrm{Et}$ constituit bellum aduersus Ptolomeum regem Aegypti, et ueritus est Ptolomeus a facie eius et fugiit, et ceciderunt uulnerati multi. ${ }^{19} \mathrm{Et}$ conprehendit ciuitates munitas in terra Aegypti, et accepit spolia terrae Aegypti multa ualde. ${ }^{20} \mathrm{Et}$ conuertit Antiochus postquam percussit Aegyptum in centesimo et quadragesimo et tertio anno, et ascendit ad Israhel et ascendit in Hierosolimam in multitudine graui. ${ }^{21}$ Et intrauit in sanctificationem cum superbia, et accepit altare aureum et candelabrum luminis et uniuersa uasa eius ${ }^{22} \mathrm{et}$ mensam propositionis et libatoria et fialas et mortariola et uelum et coronas et ornamentum aureum quod erat in facie templi, et comminuit omnia. ${ }^{23} \mathrm{Et}$ accepit argentum et aurum et uasa concupiscibilia, et accepit thesauros occultos quos inuenit, ${ }^{24} \mathrm{et}$ acceptis omnibus abiit in terram suam, et fecit caedem hominum et locutus est superbiam magnam. ${ }^{25} \mathrm{Et}$ factus est planctus magnus in Israhel in omni loco eorum, ${ }^{26} \mathrm{et}$ ingemuerunt principes et seniores, uirgines et iuuenes infirmati sunt, et speciositas mulierum mutata est. ${ }^{27} \mathrm{Omnis}$ maritus sumpsit lamentum, et quae sedebat in toro maritali lugebat, ${ }^{28}$ et commota est terra super habitantes in ea, et uniuersa domus Iacob induit confusionem. ${ }^{29} \mathrm{Et}$ post duos annos dierum misit rex principem tributorum in ciuitates Iuda, et uenit in Hierusalem cum turba magna, ${ }^{30}$ et locutus est ad eos uerba pacifica in dolo, et crediderunt ei. Et inruit super ciuitatem repente et percussit eam plaga et perdidit populum multum ex Israhel, ${ }^{31} \mathrm{et}$

1.15: praeputia ] preputia $H \| \mid$ 1.16: Antiochi ] anthioci $H||$ 1.17: multitudine ]

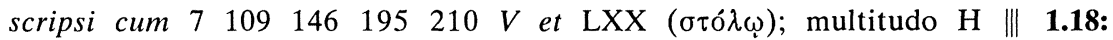
Ptolomeum ] $\mathrm{H}^{*}$; ptholomeum $\mathrm{H}^{2}$ || 1.19: conprehendit ] conpraehendit $\mathrm{H}|| \mid$ 1.20: Antiochus ] anthiocus $H|| \mid$ 1.24: locutus ] loquutus $H|| \mid$ 1.27: sedebat ] $H^{*}$ $=109146195210 \Theta^{\mathrm{AM} S} \Gamma^{\mathrm{A}}$; sedebāt $\mathrm{H}^{2}=7 \mathrm{~V} \|$ lugebat ] $\mathrm{H}^{*}=109146195210$ $\Delta^{\mathrm{M} 2} \Phi^{\mathrm{T} * 3} \Theta^{\mathrm{AM}} S \Gamma^{\mathrm{A}}$; lugebāt $\mathrm{H}^{2}=7 V|| \mathbf{1 . 3 0}$ : locutus ] loquutus $\mathrm{H} \|$ 
accepit spolia ciuitatis et succendit eam igni et destruxit domos eius et muros in circuitu. ${ }^{32} \mathrm{Et}$ captiuas duxerunt mulieres, et natos, et pecora, et possiderunt, ${ }^{33} \mathrm{et}$ aedificauerunt ciuitatem Dauid muro magno et firmo, et turribus firmis, et facta est illis in arcem. ${ }^{34} \mathrm{Et}$ posuerunt illic gentem peccatricem, uiros iniquos, et conualuerunt in ea, ${ }^{35} \mathrm{et}$ posuerunt arma et escam et congregauerunt spolia Hierusalem, et reposuerunt illic, et facti sunt in laqueum magnum. ${ }^{36} \mathrm{Et}$ facti sunt in insidias sanctificationi et in diabolum malum Israhel semper. ${ }^{37} \mathrm{Et}$ effuderunt sanguinem innocentem per circuitum sanctificationis et contaminauerunt sanctificationem. ${ }^{38} \mathrm{Et}$ fugierunt habitatores Hierusalem propter eos, et facta est habitatio exterorum et facta est extera his qui nati sunt ex ea, filii eius et reliquerunt eam, ${ }^{39}$ sanctificatio eius desolata est sicut solitudo, dies festi eius conuersi sunt in luctum, sabbata eius in obprobrium, honor eius in nihilum. ${ }^{40}$ Secundum gloriam eius multiplicata est ignominia eius, et sublimitas conuersa est in luctum. ${ }^{41} \mathrm{Et}$ scripsit rex Antiochus omni regno suo ut esset uniuersus populus unus, ${ }^{42}$ et reliquerunt unusquisque legitima sua. Et receperunt omnes gentes secundum uerbum regis, ${ }^{43}$ et multi ex Israhel consenserunt seruitio eius et sacrificauerunt simulacris et polluerunt sabbatum. ${ }^{44} \mathrm{Et}$ misit rex libros in manu nuntiorum in Hierusalem et ciuitates Iudae ut irent post legitima exterae terrae, ${ }^{45} \mathrm{et}$ prohibere holocausta et sacrificia et libationes de sanctificatione, et contaminari sabbata et dies sollemnes, ${ }^{46}$ et polluere sanctificationem et sancta, ${ }^{47}$ instruere aras, delubra et idola, et immolare porcina et pecora communia, ${ }^{48} \mathrm{et}$ relinquere filios suos incircumcisos, et polluere animas eorum in omni inmundo et abominatione, ${ }^{49}$ ita ut obliuiscerentur legis et mutarent iustificationes; ${ }^{50} \mathrm{et}$ quicumque non fecisset secundum uerbum regis moreretur. ${ }^{51}$ Secundum omnia uerba haec scripsit in uniuerso regno suo et fecit consideratores super populum; et mandauit ciuitatibus Iuda immolare per ciuitatem et ciuitatem. ${ }^{52} \mathrm{Et}$ congregati sunt de populo multi ad eos, omnes derelinquentes legem, et fecerunt mala in terra, ${ }^{53} \mathrm{et}$ posuerunt Israhel in occultis in omni refugio eorum. ${ }^{54} \mathrm{Et}$ quinta decima die mensis Chasleu, quinto et quadragesimo et centesimo anno, aedificauerunt abominationem desolationis super altare, et in ciuitatibus Iuda in circuitu struxerant aras, ${ }^{55} \mathrm{et}$ in ostiis domus et in plateis incendebant, ${ }^{56} \mathrm{et}$ libros legis inuenerunt et succenderunt

1.41: Antiochus ] anthiocus $\mathrm{H} \|$ 1.44: legitima exterae terrae ] sic $\mathrm{H}=79495$

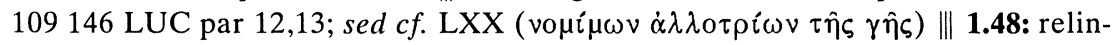

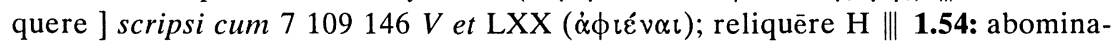
tionem ] $\mathrm{H}^{*}$; adominationem $\mathrm{H}^{2} \|$ 
igni concisos, ${ }^{57}$ et ubicumque inueniebatur apud aliquem liber testamenti et si qui consentiebat legi, constitutio regis interficiebat eum. ${ }^{58}<$ In uirtute sua faciebant ad Israhel his qui in $>$ ueniebantur in omni mense et mense in ciuitatibus. ${ }^{59} \mathrm{Et}$ quinta et uicesima mensis sacrificabant super aram quae erat super altare. ${ }^{60} \mathrm{Et}$ mulieres quae circumciderant natos suos interficiebant secundum praeceptum regis, ${ }^{61}$ et suspendebant infantes a ceruicibus eorum, in domibus eorum et eos qui circumciderant eos. ${ }^{62} \mathrm{Et}$ multi in Israhel obtinuerunt et confirmati sunt aduersus eos ut non manducarent inmunda. ${ }^{63} \mathrm{Et}$ susceperunt mori ut non polluerentur escis et non profanarent testamentum sanctum et moriebantur, ${ }^{64} \mathrm{et}$ facta est ira magna super Israhel nimis.

2.- ${ }^{1}$ In diebus illis surrexit Mathatias filius Iohannis Symeonis sacerdos filiorum Ioarib ab Hierusalem, et sedit in Modim. ${ }^{2} \mathrm{Et}$ huic erant filii quinque: Iohannes qui cognominabatur Gaddis, ${ }^{3}$ Symon qui uocabatur Thassi, ${ }^{4}$ Iudas qui uocabatur Machabeus, ${ }^{5}$ Eleazar qui uocabatur Quaran, et Ionathas qui uocabatur Apphus. ${ }^{6} \mathrm{Et}$ uidit blasphemias quae faciebant in Iudaea et Israhel, ${ }^{7} \mathrm{et}$ dixit: Heu me, ut quid istud factus sum uidere contritionem populi mei et contritionem sanctae ciuitatis? Et sederunt illic cum daretur in manus inimicorum, sanctificatio in manum exterorum. ${ }^{8}$ Factus est populus eius ut uir ingloriosus, ${ }^{9}$ uasa gloriosa eius captiua abducta sunt, interfecti sunt paruuli eius, iuuenes eius in gladio inimici. ${ }^{10} \mathrm{Quae}$ gens quae non possedit regna et non obtinuit spolia eius? ${ }^{11} \mathrm{Omnis}$ ornatus eius ablatus est, pro libera facta est ancilla. ${ }^{12}$ Ecce sancta nostra et speciositas nostra et gloria nostra desolata est, et polluerunt ea gentes. ${ }^{13} \mathrm{Et}$ quid nobis adhuc uitam? ${ }^{14} \mathrm{Et}$ conscidit Matthatias et filii eius uestimenta sua et cooperuerunt se ciliciis et luctum habuerunt ualde. ${ }^{15} \mathrm{Et}$ uenerunt qui a rege conpellabantur in Modim ciuitate ut sacrificarent. ${ }^{16} \mathrm{Et}$ multi ex Israhel

1.57: qui ] sic $\mathrm{H}=109$ ( $c f$. E. LÖFSTEDT, Syntactica [Lund 1933] vol. II, págs. 85, 88, 94); sed cf. 7146 LUC par 12,29 (quis) || 1.58: <in ... in>ueniebantur ] leg. neq. H; scripsi

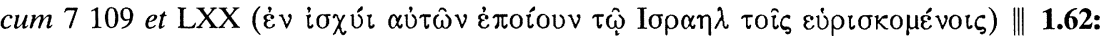
obtinuerunt ] optinuerunt $\mathrm{H} \| \mid$ 1.63: escis ] aescis H || 2.1: Modim ] sic $\mathrm{H}$; cf. 7109

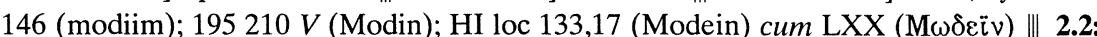
huic erant ] + br. sp. in ras. $\mathrm{H}^{2}$; illi? $\mathrm{H}^{*} \|$ Gaddis ] $\mathrm{H}^{*} ?=V$ cum $\mathrm{LXX}^{\mathrm{AV}}$ q-74 5425556106 ( $\gamma \alpha[\delta] \delta[\varepsilon] \iota \varsigma)$; gaddi $\mathrm{H}^{2}=7109146195210$ cum LXX: $\Gamma \alpha \delta \delta \imath$ || 2.5: Quaran ] sic H, pro Auaran?; cf. LXX (A $\vee \alpha \rho \alpha v)|| \mid$ 2.6: Israhel ] sic $\mathrm{H}=109$ (israhel) et LUC par 12,42;

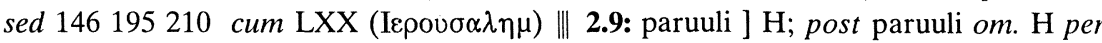

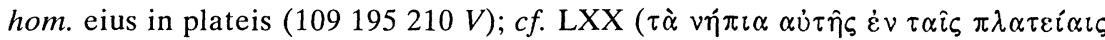

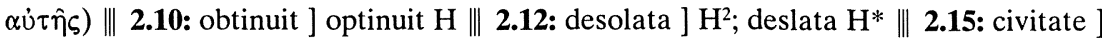

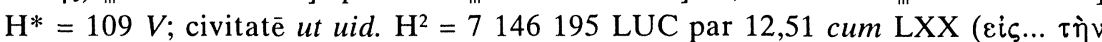
$\pi o ́ \lambda \iota v) ; c f . \Pi^{\mathrm{G}^{2}} \mathrm{M}^{2} \Phi^{\mathrm{T} 2} \Theta^{\mathrm{AM}} Z^{* 3} \Psi^{\mathrm{D}}$ (in civitatem Modin) $\|$ 
accesserunt ad eos, et Matthatias et filii eius congregati sunt. ${ }^{17} \mathrm{Et}$ responderunt hi qui a rege et aiunt Matthatiae dicentes: Princeps et nobilis et magnus es in ciuitate ista et confirmatus filiis et fratribus; ${ }^{18}$ nunc accede primus et fac imperium regis, sicut fecerunt omnes gentes et uiri Iuda et qui derelicti sunt in Hierusalem, et eris tu et filii tui amici regis et tu et filii tui glorificaueris argento et auro et muneribus multis. ${ }^{19} \mathrm{Et}$ respondit Matthatias et dixit uoce magna: $\mathrm{Si}$ omnes gentes quae in domo regis audiunt eum ut discedat unusquisque $a b$ officio patrum suorum et elegerunt in mandatis eius, ${ }^{20}$ nam ego et filii mei et fratres mei ibimus in testamento patrum nostrorum. ${ }^{21}$ Potius est nobis non derelinquere legem et iustificationes. ${ }^{22}$ Uerbum autem regis non audiemus ut praetereamus officium deseruitionis nostrae dextra uel sinistra. ${ }^{23}$ Et ut cessauit loqui, accessit uir Iudaeus in oculis omnium sacrificare in Modin ciuitate secundum praeceptum regis. ${ }^{24} \mathrm{Et}$ uidit Matthatias et zelatus est, <et contremuerunt renes eius $>$, et attulit iram secundum iudicium, et aduersus eos ad aram interficit eum, ${ }^{25}$ et uirum regis qui cogebat immolare occidit in illo tempore, et aram destruxit. ${ }^{26} \mathrm{Et}$ aemulatus est in lege sicut fecit Finees Zambri filio Salon. ${ }^{27} \mathrm{Et}$ exclamauit Mathatias in ciuitate uoce magna dicens: Omnis aemulus statuens testamentum exeat post me. ${ }^{28} \mathrm{Et}$ fugiit ipse et filii eius in montes, et reliquerunt quaecumque habebant in ciuitate. ${ }^{29}$ Tunc descenderunt multi quaerentes iustitiam et iudicium in desertum sedere ibi, ${ }^{30}$ et filii illorum et mulieres ipsorum et pecora eorum, quoniam indurauerant super eos mala. ${ }^{31} \mathrm{Et}$ renuntiatum est uiris regis, et uirtutes quae erant in Hierusalem ciuitate Dauid, quoniam descenderunt uiri qui dissipauerant mandatum regis in occultis in deserto. ${ }^{32} \mathrm{Et}$ cucurrerunt post illos multi et comprehenderunt eos et admouerunt ad eos et constituerunt aduersus eos proelium in die sabbatorum, ${ }^{33}$ et dixerunt ad eos: Et quo hoc nunc! exite et facite secundum uoluntatem regis, et uiuetis. ${ }^{34} \mathrm{Et}$ dixerunt: Non ibimus neque faciemus uerbum regis ut polluamus diem sabbatorum. ${ }^{35} \mathrm{Et}$ concitauerunt aduersus eos proelium; ${ }^{36}$ et non responderunt illis, non lapidem miserunt eis neque oppilauerunt loca occulta, ${ }^{37}$ dicentes: Moriamur omnes in simplicitate nostra; teste est super nos caelum et terra quod iniuste perditis nos.

2.18: accede ] $\mathrm{H}^{2}$; acede $\mathrm{H}^{*}||$ 2.22: regis ] is leg. neq. $\mathrm{H}$; scripsi cum 7109146

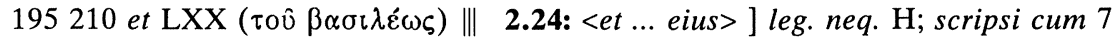

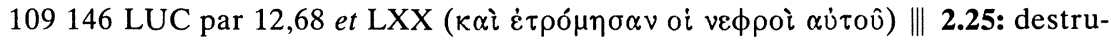
xit ] dextruxit $\mathrm{H}|| \mid$ 2.26: aemulatus ] ęmulatus $\mathrm{H} \|$ Finees ] ut uid. $\mathrm{H}|| \mid$ 2.31: renuntiatum ] ntiat eras.? $\mathrm{H} \|$ uirtutes ] utes ut uid. $\mathrm{H} \|$ 2.32: ad eos ] ut uid. $\mathrm{H} \|$ $\left.\operatorname{eos}^{2}\right] \mathrm{H}=$ rel. lat.; + br. sp. in ras. $\mathrm{H}^{2} ;+$ in? $\mathrm{H}^{*}||$ 2.35: eos ] scripsi cum 7109

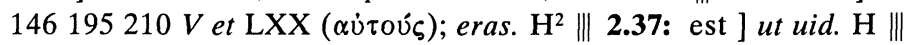


${ }^{38} \mathrm{Et}$ surrexerunt in eos in bello sabbatis, et mortui sunt ipsi et uxores eorum, filii eorum et pecora eorum usque ad mille animas hominum. ${ }^{39} \mathrm{Et}$ cognouit Matthatias et amici eius, et luctum habuerunt super eos ualde, ${ }^{40}$ et dixit uir proximo suo: $\mathrm{Si}$ omnes fecerimus sicut fratres nostri fecerunt, et non pugnauerimus aduersus gentes pro anima nostra et iustificationibus nostris, nunc citius disperdent nos a terra. ${ }^{41} \mathrm{Et}$ cogitauerunt in die illa dicentes: Omnis homo quicumque uenerit ad nos in bello die sabbatorum, pugnemus aduersus eum, et non moriemur omnes, sicut mortui sunt fratres nostri in occultis. ${ }^{42}$ Tunc congregati sunt ad eos conuentus Assidaeorum fortis uiribus ab Israhel, omnis uoluntarius in lege, ${ }^{43} \mathrm{et}$ omnes qui fugiebant a malis additi sunt ad eos et facti sunt illis in firmamentum. ${ }^{44}$ Et constituerunt uirtutem et percusserunt peccatores in ira sua et uiros iniquos in indignatione et ceteri fugerunt ad nationes ut se liberarent. ${ }^{45} \mathrm{Et}$ circumiuit Matthatias et amici eius et destruxerunt aras, ${ }^{46}$ et circumciderunt pueros incircumcisos quotquot inuenerunt in finibus Israhel in fortitudine, ${ }^{47} \mathrm{et}$ persecuti sunt filios superbiae, et prosperauit opus in manibus eorum. ${ }^{48} \mathrm{Et}$ obtinuerunt legem de manibus gentium et regnum et non dederunt cornu peccatori. ${ }^{49} \mathrm{Et}$ adpropinquauerunt dies Matthatiae moriendi, et dixit filiis suis: Nunc confirmata est superbia et castigatio et tempus euersionis et ira indignationis. ${ }^{50} \mathrm{Nunc}$, filii, aemuli estote legis et date animas uestras pro testamento patrum nostrorum, ${ }^{51} \mathrm{et}$ mementote operum patrum quae fecerunt in saeculis suis, et accipietis gloriam magnam et nomen aeternum. ${ }^{52} \mathrm{Abraam}$ non in temptatione inuentus est fidelis, et reputatum est ei ad iustitiam? ${ }^{53}$ Ioseph in tempore angustiae suae custodiuit mandatum et factus est dominus Aegypti. ${ }^{54}$ Finees pater noster in zelando zelum accepit testamentum sacerdotii aeterni. ${ }^{55}$ Hiesus, dum implet uerbum, factus est iudex in Israhel. ${ }^{56} \mathrm{Chaleb}$, dum testificatur in ecclesia, accepit hereditatem. ${ }^{57}$ Dauid in sua misericordia consecutus est sedem regni in saecula. ${ }^{58}$ Helias, dum zelat zelum legis, receptus est in caelum. ${ }^{59}$ Ananias, Azarias, Misahel credentes liberati sunt

2.38: mille ] ut uid. $\mathrm{H} \| \mid$ 2.39: Matthatias ] s leg. neq. $\mathrm{H} \| \mid$ 2.40: terra ] ut uid. $\mathrm{H} \|$ 2.41: omnes ] m leg. neq. $\mathrm{H}||$ 2.42: Asidaeorum ] assi dęorum $\mathrm{H} \| \mid$ 2.45: amici ] $\mathrm{H}^{2}=$ $7109146 V$ LUC con 9,8; $c f$. 195 210; inimici $\mathrm{H}^{*} \|$ 2.47: persecuti sunt ] persequuti sunt, ut uid. $\mathrm{H} \|$ 2.48: obtinuerunt ] optinuerunt $\mathrm{H} \|$ regnum ] sic $\mathrm{H}$; sed cf. 7109146 $195210 \mathrm{~V}$ (regum) cum LXX ( $\beta \alpha \sigma \iota \lambda \varepsilon ́ \omega v) \|$ et non dederunt ] ut uid. $\mathrm{H} \| \mid$ 2.49: adpropinquauerunt ] ut uid. $\mathrm{H}|| \mid$ 2.50: filii ] scripsi cum $7146195210 \mathrm{~V}$ et LXX ( $\varepsilon ́ \kappa v \alpha$ ); fili $\mathrm{H}=\Phi^{\mathrm{T}^{*}} \mathrm{Q}^{*} \|$ 2.52: Abraam ] $\mathrm{H}^{*}=195 \mathrm{QU}$ pro 1,17,12 (Abram) cum LXX $(\mathrm{A} \beta \rho \alpha \alpha \mu)$; abraham $\mathrm{H}^{2}=7109146210 \mathrm{~V}$ CY te 3,15,15; AMst q 43,1; 117 , 6ss; AU Ps 137,6,3; PS-AU spe 28 (438,8); LUC par 15,25; QU virt 6,12; 7,7 || 2.54: aeterni ] ut uid. $\mathrm{H} \|$ 2.57: consecutus ] consequutus $\mathrm{H} \|$ 2.59: Ananias ] $\mathrm{H}^{*}=7109146195 \mathrm{~V}$; anania $\mathrm{H}^{2}=\Pi^{\mathrm{G}} \|$ 
de flamma. ${ }^{60}$ Daniel in sua simplicitate liberatus est de ore leonum. ${ }^{61} \mathrm{Et}$ ita cogitate per generationem et generationem quia omnes qui sperant in eum non infirmabuntur; ${ }^{62} \mathrm{et}$ a uerbis uiri peccatoris non timueritis, quia gloria eius in stercora et in uermibus; ${ }^{63}$ hodie extollitur et cras non inuenietur, quia conuersus est in terram suam, et cogitatio eius peribit. ${ }^{64}$ Filii, confortamini et praeualete in lege quia in ipsa gloriosi eritis. ${ }^{65}$ Ecce Symeon frater uester, scio quia uir consilii sit; ipsum audite, ipse erit pater uobis. ${ }^{66} \mathrm{Et}$ Iudas Machabeus, fortis uiribus a iuuentute sua, sit uobis princeps militiae et depugnauit bellum. ${ }^{67} \mathrm{Et}$ uos adducetis ad uos factores legis, et uindicate uindictam populi uestri. ${ }^{68}$ Retribuite retributionem gentibus et intendite in praeceptum legis. ${ }^{69} \mathrm{Et}$ benedixit eos et adpositus est ad patres suos, ${ }^{70} \mathrm{et}$ defunctus est in sexto et quadragesimo et centesimo anno, et sepultus est in sepulchris patrum suorum in Modiim, et planxerunt eum omnis Israhel planctu magno.

3.- ${ }^{1}$ Et surrexit Iudas, qui uocabatur Machabeus, filius eius, pro eo. ${ }^{2} \mathrm{Et}$ adiuuabant eum omnes fratres eius et uniuersi qui se coniunxerant patri eius et proeliabatur proelium Israhel cum laetitia. ${ }^{3}$ Et dilatauit gloriam populo et induit se lorica sicut gigans et succinxit se uasa bellica sua et proelia constituit, protegens castra gladio. ${ }^{4}$ Et similis factus est leoni in operibus suis et sicut catulus leonis [in operibus suis] rugiens in uenationem, ${ }^{5}<$ et $>$ persecutus est iniquos perscrutans, <et $>$ eos qui conturbabant populum suum succendit. ${ }^{6}$ Et subducti sunt iniqui prae timore eius, et omnes operarii iniquitatis conturbati sunt, et prospera facta est salus in manu eius. ${ }^{7}$ Et exacerbabat reges multos et delectabat Iacob in operibus suis, et usque in saeculum memoria ipsius in benedictione. ${ }^{8} \mathrm{Et}$ perambulauit in ciuitates Iuda et disperdit impios omnes ex ea et auertit iram ab Israhel. ${ }^{9}$ Et nominatus est usque ad nouissimum terrae et congregauit pereuntes. ${ }^{10} \mathrm{Et}$ congregauit Apollonius gentes et a Samaria uirtutem magnam ad bellandum contra Israhel. ${ }^{11}$ Et cognouit Iudas et exiit ei obuiam et percussit eum et occidit; et ceciderunt uulnerati multi, et reliqui fugierunt. ${ }^{12} \mathrm{Et}$ accepit

2.60: Daniel ] H $\mathrm{H}^{2}=7109146195210 \mathrm{~V}$ cum LXX $(\Delta \alpha \nu \imath \eta \lambda)$; Dauid $\mathrm{H}^{*} \|$ de ore ]

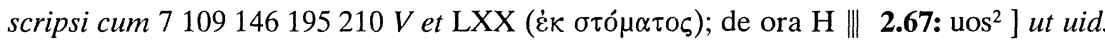
$\mathrm{H} \|$ 2.68: in ] in in $\mathrm{H} \|$ praeceptum ] pręceptum $\mathrm{H} \|$ 3.2: coniunxerant ] coniuncxerant $\mathrm{H}|| \mid$ 3.3: succinxit ] succincxit $\mathrm{H} \|$ 3.4: [in operibus suis] ] $\mathrm{H}$; del. cum 7109

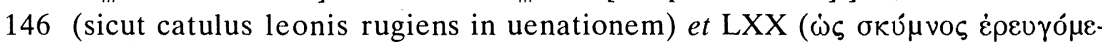

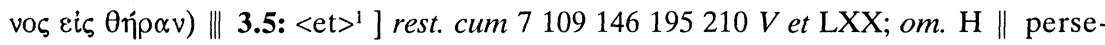
cutus ] persequutus $\mathrm{H} \|<\mathrm{et}\rangle^{2}$ ] rest. cum $109146195 \mathrm{~V}$ et $\mathrm{LXX}$; om. $\mathrm{H}=7|| \mid$ 3.7: exacerbabat ] exaceruabat $\mathrm{H}^{*}$; abat (ut uid.) eras. $\mathrm{H}^{2} \|$ delectabat ] delectauat $\mathrm{H} \|$ 
spolia eorum, et gladium Apollonii accepit Iudas, et erat pugnans in eo omnibus diebus. ${ }^{13}$ Et audiuit Seron princeps exercitus Syriae quod congregauit Iudas congregationem et conuocationem fidelium secum et egredientium in proelium, ${ }^{14} \mathrm{et}$ ait: Faciam mihi nomen et glorificabor in regno et debellabo Iudam et eos qui cum ipso sunt, qui spernunt uerbum regis. ${ }^{15} \mathrm{Et}$ addidit, et ascenderunt cum eo castra impiorum, fortes auxiliarii et ut faceret uindictam in filios Israhel. ${ }^{16} \mathrm{Et}$ adpropiauerunt usque Bethoron, et exiit Iudas in obuiam illi cum paucis. ${ }^{17} \mathrm{Ut}$ uidit autem exercitum uenientem sibi obuiam, dixerunt Iudae: Quid poterimus pauci pugnare, ad multitudinem tantam fortem? Et nos fatigati sumus ieiunio hodie. ${ }^{18} \mathrm{Et}$ ait Iudas: Facile est concludi multos in manibus paucorum, et non est differentia in conspectu caeli liberare in multis aut in paucis, ${ }^{19}$ quia non in multitudine exercitus uictoria belli, sed de caelo fortitudo. ${ }^{20}$ Ipsi ueniunt ad nos in multitudine contumeliae et iniuriae ut disperdant nos et uxores nostras et filios nostros et spolient nos; ${ }^{21}$ nos uero pugnamus pro animabus nostris, ${ }^{22}$ et Dominus conteret eos ante faciem uestram; uos autem ne timueritis eos. ${ }^{23} \mathrm{Ut}$ autem cessauit loqui, insiliit in eos subito, et contristatus est Seron et exercitus eius in conspectu ipsius. ${ }^{24} \mathrm{Et}$ persequebatur eos in deserto Bethoron usque ad campum; et ceciderunt ex eis uiri DCCC, reliqui autem fugierunt in terram Phylisthim. ${ }^{25}$ Et coepit timor esse Iudae et fratrum eius, et formido cecidit super gentes in circuitu eorum. ${ }^{26}$ Et peruenit ad regem nomen eius, propter proelia Iuda expectabat gentes. ${ }^{27} \mathrm{Ut}$ audiuit autem Antiochus sermones istos, iratus est animo et misit et congregauit exercitum uniuersum regni sui castra fortia ualde. ${ }^{28} \mathrm{Et}$ aperuit aerarium suum et dedit stipendia exercitui in annum, et mandauit illis ut essent parati ad omnia.

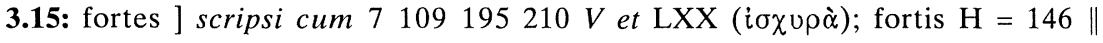
auxiliarii et ] sic $\mathrm{H}(c f .7195210 \mathrm{~V})$, sed $\mathrm{LXX}(\beta \circ \eta \theta \hat{\eta} \sigma \alpha \iota \alpha \dot{\tau} \tau \hat{\omega}) \| \mid$ 3.17: ad

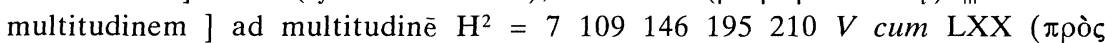
$\pi \lambda \hat{\eta} \theta \circ \varsigma$ ); a multitudine $\mathrm{H}^{*} \|$ fortem et ] fortē et ut uid. $\mathrm{H} \|$ 3.18: in manibus ] $\mathrm{H}^{*}=7109146195 \Theta^{\mathrm{AM}} \Gamma^{\mathrm{A}}$ cum LXX ( $\left.\dot{\varepsilon} \vee \chi \varepsilon \rho \sigma i v\right)$; in manus $\mathrm{H}^{2}=210 \mathrm{~V}$ SED-S rect 15 (318C) ||| 3.21: nostris ] post nostris om. $\mathrm{H}$ per hom. et pro legitimis nos-

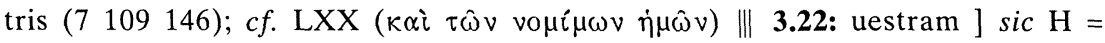

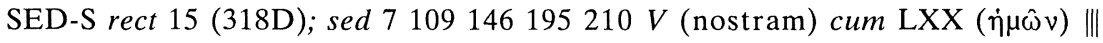

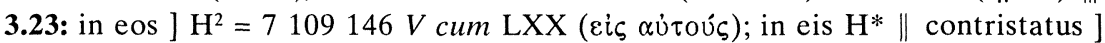
$\mathrm{H}^{*}$; contritus $\mathrm{H}^{2}=7109146195210 \mathrm{~V} \|$ exercitus ] citus leg. neq. $\mathrm{H} \| \mid \mathbf{3 . 2 4}$ : eos ] ut uid. $\mathrm{H} \|$ ceciderunt ] cid leg. neq. $\mathrm{H} \|$ Phylisthim ] $\mathrm{H}^{*}$; phylisthiim $\mathrm{H}^{2} \|$ 3.25: Iudae ] scripsi cum $7109146195210 \mathrm{~V}$ et LXX (Iovoov); iuda H || 3.26: peruenit ] er leg. neq. $\mathrm{H}||$ 3.27: Antiochus ] anthiocus $\mathrm{H} \|$ congregauit ] congregrauit $\mathrm{H}^{2}$; congregrouit $\mathrm{H}^{*} \|$ 
${ }^{29} \mathrm{Et}$ uidit quod defecit pecunia de thesauris, et tributa regionis modica propter dissensionem et plagam quam fecit in terra ut tolleret legitima quae erant a primis diebus. ${ }^{30} \mathrm{Et}$ timuit ne non haberet et semel et bis in sumptus et donatiua quae dederat ante larga manu et abundauerat super reges qui ante eum fuerant. ${ }^{31} \mathrm{Et}$ consternatus erat animo ualde et cogitauit ire in Persidem et accipere tributa regionum et congregare argentum multum. ${ }^{32} \mathrm{Et}$ reliquit Lysiam, hominem nobilem de genere regio, super negotia regis a flumine Eufraten usque ad flumen Aegypti, ${ }^{33}$ et ut nutriret Antiochum filium suum, donec rediret. ${ }^{34} \mathrm{Et}$ tradidit ei dimidium exercitum et elefantos, et mandauit ei de omnibus quae uolebat et de inhabitantibus Iudaeam et Hierusalem, ${ }^{35}$ mittere ad eos exercitum ad conterendam et extirpandam uirtutem Israhel et reliquias Hierusalem, et auferendam memoriam eorum de loco, ${ }^{36}$ et constituere habitantes filios alienigenas in omnibus finibus eorum, et possidere sorte et distribuere terram eorum. ${ }^{37} \mathrm{Et}$ rex adsumpsit dimidium exercitum residuum, et exiit ab Antiochia de ciuitate regni sui anno septimo et quadragesimo et centesimo, et transfretauit Eufraten flumen et perambulabat superiores regiones. ${ }^{38} \mathrm{Et}$ elegit Lysias Ptolomeum et Dorimenem et Nicanorem et Gorgiam, uiros potentes amicos regis. ${ }^{39} \mathrm{Et}$ misit cum eis quadraginta milia uirorum et VII milia equitum, ut uenirent in terram Iudam et disperderent secundum uerbum regis. ${ }^{40} \mathrm{Et}$ processerunt in uniuersa uirtute sua, et uenerunt et adplicuerunt Ammaum in terra campestri. ${ }^{41} \mathrm{Et}$ audierunt mercatores regionis nomen eorum, et acceperunt argentum et aurum multum ualde et pueros, et uenerunt in castra, ut acciperent filios Israhel in pueros, et additi sunt ad eos exercitus Syriae de terra alienigenarum. ${ }^{42} \mathrm{Et}$ uidit Iudas et fratres eius quia multiplicata sunt mala, et exercitus adplicabant ad fines eorum, et cognouerunt uerba regis quae mandauit facere populo in interitum et consummationem. ${ }^{43} \mathrm{Et}$ dixerunt unusquisque ad proximum suum: Suscitemus purgationem populi nostri et pugnemus pro populo nostro et pro sanctis nostris. ${ }^{44} \mathrm{Et}$ congregatus est conuentus, ut essent parati in proelium et ut orarent et peterent

3.29: quae ] que $\mathrm{H} \|$ 3.30: $\mathrm{e}^{2}$ ] sic $\mathrm{H}=V$, sed cf. $7109146 \Theta^{\mathrm{AM}^{*}} \Gamma^{\mathrm{A}} \Omega^{\mathrm{J} 2(\text { in ras.) }}$ (ut) cum LXX $(\dot{\omega} \varsigma) \|$ quae ] quę $\mathrm{H} \|$ abundauerat ] habundauerat $\mathrm{H} \|$ 3.32: reliquit ] reliquid $\mathrm{H} \| \mid \mathbf{3 . 3 3}$ : Antiochum ] anthiocum $\mathrm{H} \|$ 3.34: elefantos ] $\mathrm{H}^{*}=7109146$ $195210 \mathrm{~V}$; elefantes $\mathrm{H}^{2}=\mathrm{M}^{*}$ (ut uid.) $\Omega^{\mathrm{M}} \|$ Iudaeam ] iudęam $\mathrm{H} \|$ 3.36: constituere

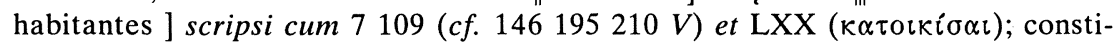
tuere habentes $\mathrm{H} \|$ alienigenas ] $\mathrm{H}^{*}$; alienigeni? $\mathrm{H}^{2}||$ 3.37: Antiochia ] anthiocia H || 3.38: Ptolomeum ] tholomeum H || 3.39: VII ] VĪī H || 3.40: Ammaum ] scripsi cum $7109146195210 \mathrm{~V}$ et $\mathrm{LXX}^{62-542} 46106340$ ( $\left.\alpha \mu \mu \alpha \mathrm{\alpha} \mu \mu\right)$; anomaum H $\|$ 3.41: uenerunt ] uęnerunt $H \| \mid$ 3.42: consummationem ] consumationem $H \| \mid$ 3.44: congregatus ] $\mathrm{H}^{2}$; congregats $\mathrm{H}^{*} \|$ 
misericordiam et miserationes. ${ }^{45}$ Et Hierusalem non inhabitabatur sicut desertum, non erat qui ingrederetur et egrederetur de generationibus eius, et sanctum conculcabatur, et filii alienigenarum in arce, habitatio gentium, et ablata est uoluptas Iacob, et defecit tibia et cinyra. ${ }^{46} \mathrm{Et}$ congregati sunt et uenerunt in Maspha ante Israhel. ${ }^{47} \mathrm{Et}$ ieiunauerunt illa die et induerunt se ciliciis et cinerem in capite suo et sciderunt uestimenta sua, ${ }^{48}$ et expanderunt libros legis de quibus scrutabantur gentes et similitudines simulacrorum suorum, ${ }^{49}$ et adtulerunt uestimenta sacerdotalia et primitias et decimas, et suscitauerunt nazoreos qui impleuerant dies, ${ }^{50} \mathrm{et}$ clamauerunt uoce magna in caelum dicentes: Quid faciemus istis et quo eos ducemus? ${ }^{51} \mathrm{Et}$ sancta tua conculcata sunt et contaminata, et sacerdotes tui in luctu et humiliatione. ${ }^{52} \mathrm{Et}$ ecce nationes conuenerunt aduersum nos ut nos disperdant; tu scis quae cogitant in nos. ${ }^{53}$ Quomodo poterimus subsistere ante faciem illorum, nisi tu adiuues nos? ${ }^{54} \mathrm{Et}$ tubis exclamauerunt uoce magna. ${ }^{55} \mathrm{Et}$ post hoc constituit Iudas duces populi: tribunos et centuriones. ${ }^{56}$ Dixitque his qui aedificabant domos et sponsabant uxores et plantabant uineas et formidolosis, redive unusquisque in domum suam secundum legem. ${ }^{57} \mathrm{Et}$ mouerunt castra et adplicuerunt contra austrum Ammaum. ${ }^{58} \mathrm{Et}$ ait Iudas: Accingimini et estote in filios potentes, et estote parati in mane, ut pugnetis aduersus nationes has quae conuenerunt disperdere nos et sancta nostra; ${ }^{59}$ quoniam melius est nos mori in bello quam respicere in mala gentis nostrae et sanctorum. ${ }^{60}$ Sicut autem fuerit uoluntas in caelo, sic fiat!

4. - ${ }^{1}$ Et adsumpsit Gorgias $\mathrm{V}$ milia uirorum et mille equites electos. Et mouerunt castra tota nocte, ${ }^{2}$ ut adplicarent ad castra Iudaeorum et percuterent eos subito, et filii summae arcis erant illi duces. ${ }^{3} \mathrm{Et}$ audiuit Iudas et surrexit ipse et potentes percutere uirtutem exercituum regis qui in Ammaum, ${ }^{4}$ dum adhuc dispersus erat exercitus a castris. ${ }^{5}$ Et uenit Gorgias in castra Iuda nocte et neminem inuenit, et quaerebat eos in montibus, quoniam dixit: Fugiunt hii a nobis. ${ }^{6} \mathrm{Et}$ simul ut dies factus est, apparuit Iudas in campo in tribus milibus uiris, tantum quod tegimenta et gladios

3.45: conculcabatur ] ulc leg. neq. $\mathrm{H} \| \mathrm{et}^{4}$ ] leg. neq. $\mathrm{H} \|$ cinyra ] cynyra $\mathrm{H}^{*}$; $c$. $\mathrm{LXX}$ ( $\iota \vee \cup ́ \rho \alpha$ ); cynara $\mathrm{H}^{2}=109 \|$ 3.46: Maspha ] post Maspha om. $\mathrm{H}$ per hom. contra

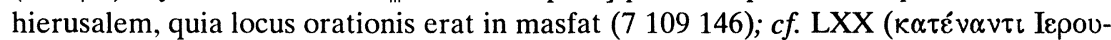

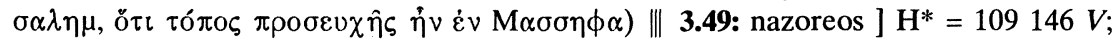

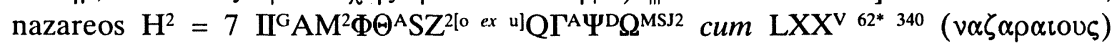
|| 3.52: disperdant ] nt leg. neq. $\mathrm{H} \|$ quae ] que $\mathrm{H}|| \mid$ 3.57: Ammaum ] anmaū $\mathrm{H} \|$ 3.58: estote $^{1}$ ] $\mathrm{H}^{2}=7109146195210^{2} V$; stote $\mathrm{H}^{*}=210^{*} \|$ 3.60: uoluntas ] uolumptas $\mathrm{H} \|$ 4.2: Iudaeorum ] iudeorum $\mathrm{H} \| \mid$ 4.3: audiuit ] $\mathrm{H}^{2}$; adiuit $\mathrm{H}^{*} \|$ exercituum ] $\mathrm{H}^{2}$; exercituu? $\mathrm{H}^{*}||$ 4.6: [et] ] del. cum 7109146 et LXX || 
non habebant, [et] ut uolebant ${ }^{7}<$ et $>$ uiderunt castra gentium ualida et loricatos et equitatum in circuitu eorum, et hii docti ad proelium. ${ }^{8} \mathrm{Et}$ ait Iudas uiris qui secum erant: Ne timueritis multitudinem illorum, et impetum eorum ne formidetis. ${ }^{9}$ Mementote qualiter salui facti sunt patres nostri in Mari Rubro, cum sequeretur eos Pharao cum exercitu. ${ }^{10} \mathrm{Et}$ nunc clamemus in caelum, si miserebitur nostri et memor erit testamenti patrum, et conteret exercitum hodie, ${ }^{11}$ et scient omnes gentes quia est Deus qui redimat et liberet Israhel. ${ }^{12} \mathrm{Et}$ leuauerunt alienigenae oculos suos et uiderunt eos uenientes ex aduerso. ${ }^{13} \mathrm{Et}$ exierunt de castris in proelium, et tuba cecinerunt ex parte Iuda, ${ }^{14} \mathrm{et}$ commiserunt et contritae sunt gentes et fugierunt in campum. ${ }^{15}$ Nouissimi autem omnes ceciderunt gladio, et persecuti sunt eos usque Azeron et usque in campos Idumeae et Azoti et Iamniae, et ceciderunt ex illis ad uirorum tria milia. ${ }^{16} \mathrm{Et}$ reuersus est Iudas et exercitus eius insequens eos, ${ }^{17}$ dixitque ad populum: Non concupiscatis spolia, quia bellum contra nos est, ${ }^{18}$ et Gorgias et exercitus in monte prope nos est; sed state nunc contra inimicos uestros et expugnate eos, et post haec sumetis spolia securi. ${ }^{19}$ Adhuc loquente Iuda, ecce apparuit pars quaedam prospiciens de monte. ${ }^{20} \mathrm{Et}$ uidit quod in fugam conuersi sunt et succenderunt castra: fumus enim qui uidebatur declarabat quod factum est. ${ }^{21}$ Quibus illi conspectis, timuerunt ualde; aspicientes uero et Iudae exercitum in campo paratum ad proelium, ${ }^{22}$ fugierunt omnes in terram alienigenarum. ${ }^{23} \mathrm{Et}$ Iudas regressus est ad spolia castrorum, et acceperunt aurum multum et argentum et hyacinthum et purpuram marinam et opes magnas. ${ }^{24} \mathrm{Et}$ conuersi hymnum canebant et benedicebant in caelum quoniam bonus, quoniam in saeculum misericordia eius. ${ }^{25} \mathrm{Et}$ facta est salus magna in Israhel in die illa. ${ }^{26}$ Quicumque autem alienigenarum euasit et uenerunt et nuntiauerunt Lysiae uniuersa quae acciderant.

4.7: <et> ] scripsi cum $7109146195210 \mathrm{~V}$ et $\mathrm{LXX} \|$ ualida ] $\mathrm{H}^{*}=109146 \mathrm{~V}$; ualidas? $\mathrm{H}^{2} \|$ equitatum ] scripsi cum $7109146 \Phi^{\mathrm{T}^{* \mathrm{R}}}$ et $\mathrm{LXX}$ ( ${ }^{\circ} \pi \pi \mathrm{ov}$ ); equitum $\mathrm{H}$ || 4.9: cum ] quum $\mathrm{H} \|$ exercitu ] $\mathrm{H}^{2}$; exercetu $\mathrm{H}^{*} \|$ 4.10: et nunc clamemus ] et nunc clame in ras. $\mathrm{H}^{2}$; leg. neq. $\mathrm{H}^{*} \|$ exercitum hodie ] sic $\mathrm{H}$; ante hodie om. $\mathrm{H}$

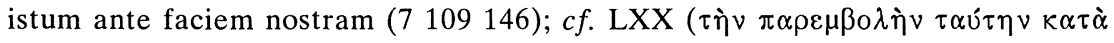

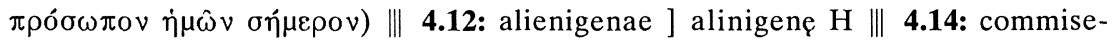
runt ] co leg. neq. H; cf. 7109146195210 || contritae ] contritę $\mathrm{H} \|||$ 4.15: persecuti ] persequuti $\mathrm{H} \|$ Azeron ] sic $\mathrm{H}$, sed cf. 7 (gazzeron), 109 (gazoron), 146 (gazaron), 195 (gazeron), $V$ (Gesoron) et LXX (Г $\alpha \eta \rho \omega \nu)$; $c f$. F. M. ABEL, «Topographie des campagnes Machabéens», Revue Biblique 32 (1923) pág. 508 ||| 4.23: hyacinthum ] yachintum $\mathrm{H}|| \mid$ 4.26: euasit ] sic $\mathrm{H}$; sed cf. $7109146 \mathrm{~V}$ (euaserunt) cum $\operatorname{LXX}(\delta\llcorner\varepsilon \sigma \omega \theta \eta \sigma \alpha \nu) \|$ 
${ }^{27}$ Quibus ille auditis, consternatus est et animo deficiebat, quod non qualia uoluit talia contigerunt Israhel, et non qualia mandauerat rex euenerant. ${ }^{28} \mathrm{Et}$ in sequenti anno congregauit uirorum electorum LX milia et V milia equitum, ut debellaret eos. ${ }^{29} \mathrm{Et}$ uenerunt in Idumeam et admouerunt in Bethosuris, et obuiauit illis Iudas $\mathrm{X}$ milia habens uirorum. ${ }^{30} \mathrm{Et}$ uiderunt exercitum fortem, et orauit et dixit: Benedictus es, saluator Israhel, qui contriuisti impetum potentis in manu serui tui Dauid et tradidisti castra alienigenarum in manus Ionathae filii Saul et portantis arma eius; ${ }^{31}$ conclude exercitum istum in manu populi tui Israhel, et confundatur in uirtute et equitibus. ${ }^{32} \mathrm{Da}$ illis formidinem et tabefac audaciam uirtutis eorum, et commoueantur uirtute sua; ${ }^{33} \mathrm{et}$ deice eos gladio diligentium te, et conlaudabunt te omnes qui nouerunt nomen tuum in hymnis. ${ }^{34} \mathrm{Et}$ commiserunt ad inuicem, et ceciderunt de exercitu Lysiae quinque milia uirorum et prociderunt ex aduerso eorum. ${ }^{35}$ Ut uidit autem Lysias in fugam conuersam esse aciem suam, Iudae uero audaciam et quemadmodum parati sunt aut uiuere aut mori fortiter, abiit in Antiochiam et elegit milites ut multiplicatus rursus ueniret in Iudaeam. ${ }^{36}$ Dixit autem Iudas et fratres eius: Ecce contriti sunt inimici nostri, ascendamus mundare sancta et renouare. ${ }^{37} \mathrm{Et}$ congregatus est omnis exercitus, et ascenderunt in montem Sion, ${ }^{38} \mathrm{et}$ uiderunt sanctificationem desertam et altare profanatum et portas conbustas et in atriis uirgulta nata sicut in saltu aut in uno montium et pastoforia diruta. ${ }^{39} \mathrm{Et}$ planxerunt planctu magno et inposuerunt cinerem, ${ }^{40} \mathrm{et}$ ceciderunt in faciem super terram et exclamauerunt tubis signorum et clamauerunt in caelum. ${ }^{41}$ Tunc ordinauit Iudas uiros ut pugnarent aduersus eos qui erant in arce, donec mundaret sancta. ${ }^{42} \mathrm{Et}$ elegit sacerdotes sine macula, uoluntarios legis. ${ }^{43} \mathrm{Et}$ mundauerunt sancta et tulerunt lapides contaminationis in locum inmundum. ${ }^{44} \mathrm{Et}$ cogitauit de altari holocaustorum quod profanatum erat, quid de eo faceret. ${ }^{45} \mathrm{Et}$ accidit illis consilium bonum ut demolirentur illud, ne umquam esset illis in obprobrium, quia contaminauerunt illud gentes; et demolierant illud, ${ }^{46}$ et reposuerunt lapides in monte domus, in loco alto, quoadusque ueniret propheta et responderet de eis. ${ }^{47} \mathrm{Et}$ acceperunt lapides integros secundum legem et aedificauerunt altare

4.30: Ionathae ] ionathę $\mathrm{H}|| \mid$ 4.35: abiit ] $\mathrm{H}^{2}$; habiit? $\mathrm{H}^{*} \|$ Antiochiam ] anthiociam $\mathrm{H} \|$ milites ] $\mathrm{H}^{2}=7109 \mathrm{~V}$; militer? $\mathrm{H}^{*} \|$ 4.39: et ${ }^{1}$ ] ante et om. $\mathrm{H}$ et scide-

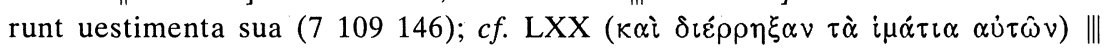
4.44: eo ] + br. sp. in ras. $\mathrm{H}^{2}$; leg. neq $\mathrm{H}^{*} \| \mid$ 4.45: demolirentur ] demoliręntur $\mathrm{H}$

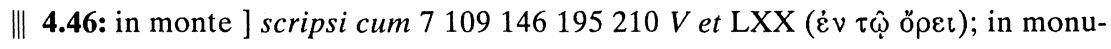
mento $\mathrm{H} \| \mid$ 
nouum secundum quod prius. ${ }^{48} \mathrm{Et}$ aedificauerunt sancta et quae intra domum [aedem], et atrium sanctificauerunt, ${ }^{49} \mathrm{et}$ fecerunt uasa sancta noua et intulerunt candelabrum et altare incensorum, et mensam in templum. ${ }^{50} \mathrm{Et}$ incenderunt super altare et accenderunt lucernas quae super candelabrum erant, et lucebant in templo. ${ }^{51} \mathrm{Et}$ posuerunt super mensam panes, et expanderunt uela, et consummauerunt omnia opera quae fecerunt. ${ }^{52} \mathrm{Et}$ ante matutinum surrexerunt quinta et uicesima mensis noni (hic mensis Chasleu) octaui et quadragesimi et centesimi anni, ${ }^{53} \mathrm{et}$ obtulerunt sacrificium secundum legem super altare holocaustorum nouum quod fecerunt; ${ }^{54}$ secundum tempus et secundum diem in qua contaminauerunt illud gentes, in ipsa renouatum est in canticis et citharis et cinyris et in cymbalis. ${ }^{55} \mathrm{Et}$ cecidit omnis populus in faciem, et adorauerunt et benedixerunt in caelum eum qui prosperauit eis. ${ }^{56} \mathrm{Et}$ fecerunt dedicationem altaris diebus octo et obtulerunt holocausta cum laetitia et sacrificauerunt sacrificium salutaris et laudis. ${ }^{57} \mathrm{Et}$ ornauerunt faciem templi coronis aureis et scutulis et dedicauerunt portas et pastoforia, et ianuas eis inposuerunt. ${ }^{58} \mathrm{Et}$ facta est laetitia in populo magna ualde, et auersatum est obprobrium gentium. ${ }^{59} \mathrm{Et}$ statuit Iudas et fratres eius et uniuersa ecclesia Israhel ut agatur dies dedicationis altaris in temporibus suis annum ad annum, dies octo a quinta et uicesima mensis Chasleu, cum laetitia et gaudio. ${ }^{60} \mathrm{Et}$ aedificauerunt in tempore illo montem Sion per circuitum, muros altos et turres firmas, ne quando uenirent gentes et conculcarent eam sicut antea fecerunt. ${ }^{61}$ Et collocauit illic exercitum ut seruarent ea et muniuit eam ad custodiendum Bethsuram, ut haberet populus munitionem secundum faciem Idumeae.

5. - ${ }^{1}$ Et factum est $<$ ut $>$ audierunt gentes in circuitu quia aedificatum est altare et aedificatum est sanctificium sicut prius, et irati sunt ualde, ${ }^{2}$ et cogitabant tollere genus Iacob, qui erant inter eos, et coeperunt occidere de populo et persequi. ${ }^{3} \mathrm{Et}$ debellabant Iudam a filiis Israhel, hoc est Esau in Idumea Araba, quia circumsedebant Israhelitas, et percusserunt eos plaga magna et contriuit

4.48: domum [aedem] ] $\mathrm{H}=7$; $c f .109$ (domum eduum) et $V$ (domum ... et ae-

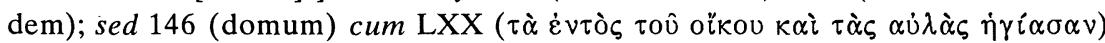
$\| \mathrm{et}^{3}$ ] in ras. $\mathrm{H}^{2}$; leg. neq. $\mathrm{H}^{*}||$ 4.52: mensis noni hic ] $\mathrm{H}^{*}$ ?; scripsi cum $7109 \mathrm{~V}$

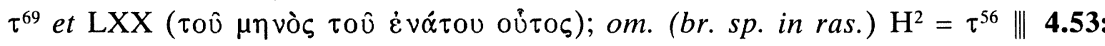
quod ] in ras. $\mathrm{H}^{2}$; leg. neq. $\mathrm{H}^{*} \|$ 4.54: citharis ] cytharis $\mathrm{H} \|$ cinyris ] cynyris $\mathrm{H} \|$ 4.58: auersatum ] $\mathrm{H}^{*}=7109$ 146; auersum $\mathrm{H}^{2}=V \|$ 4.61: seruarent ] ut uid. $\mathrm{H} \|$ 5.1: <ut> ] rest. cum 7109146 V et LXX (ő $\tau \varepsilon) ;$ om. $\mathrm{H} \|$ est ] + br. sp. in ras. $\mathrm{H}^{2}$; leg. neq. $\mathrm{H}^{*}||$ 5.3: Araba ] sic $\mathrm{H}$; $c f .109$ (et arabas); sed 7 (agrabatthine), 146 (arcebathane), 195 (acrabatene), $V$ (Acrabattene) cum LXX ( $\tau \eta \dot{v \eta} v) ; c f$. ABEL «Topographie» pág. $513 \|$ 
eos et accepit spolia eorum, ${ }^{4} \mathrm{et}$ recordatus est malitiae filiorum Bean qui erant populo in laqueum et in scandalum, insidiantes eis in uiis. ${ }^{5}$ Et conclusi sunt $\mathrm{ab}$ eo in turribus et adplicauit ad eos et deuotauit eos et incendit turres eius igni cum omnibus quae in eis erant. ${ }^{6} \mathrm{Et}$ transiit ad filios Ammon et inuenit manum fortem et populum copiosum et Timotheum ducem ipsorum. ${ }^{7} \mathrm{Et}$ commisit cum illis proelia multa, <et> contriti sunt in conspectu eorum, et percussit eos. ${ }^{8}$ Et cepit Iazer et filias eius et reuersus est in Iudaeam. ${ }^{9}$ Et congregatae sunt gentes quae sunt in Galaad aduersus Israhel, qui erant in finibus eorum, ut tollerent eos, et fugierunt in Dathem ad munitionem. ${ }^{10} \mathrm{Et}$ miserunt litteras ad Iudam et fratres eius dicentes: Congregatae sunt aduersum nos gentes per circuitum, ut nos auferant, ${ }^{11}$ et parant uenire et occupare munitionem in quam confugimus; et Timotheus est dux exercitus eorum. ${ }^{12} \mathrm{Nunc}$ ergo ueni, eripe nos de manibus eorum, quia cecidit de nobis multitudo, ${ }^{13} \mathrm{et}$ omnes fratres nostri qui erant in locis Tobin interfecti sunt, et captiuas abduxerunt uxores eorum et natos et \{quia\} perdiderunt illic fere mille uiros. ${ }^{14} \mathrm{Et}$ adhuc epistolae legebantur, et ecce nuntii alii uenerunt de Galilea, conscissis tunicis, nuntiantes secundum uerba haec, ${ }^{15}$ dicentes conuenisse aduersum se a Ptolomaida et Tyro et Sydone et omni Galilea alienigenarum ut nos consumant. ${ }^{16} \mathrm{Ut}$ audiuit autem Iudas et populus sermones istos, conuenit ecclesia magna cogitare quid facerent fratribus suis, quia in tribulatione erant et expugnabantur ab eis. ${ }^{17}$ Dixitque Iudas Symoni fratri suo: Elige tibi uiros et uade, et libera fratres nostros in Galilea; ego enim et Ionathas frater meus ibimus in Galadithin. ${ }^{18} \mathrm{Et}$ reliquit Iosephum filium Zachariae et Azariam duces populi cum residuis uirtutibus in Iudaea ad custodiendum, ${ }^{19} \mathrm{et}$ praecepit illis dicens: Praeestote populo huic et nolite bellum committere aduersus gentes donec reuertamur. ${ }^{20}$ Et partiti sunt Symon uirorum tria milia ut iret in Galileam, Iudae autem $\overline{\mathrm{VIII}}$ in Galadithin.

5.5: adplicauit ] $\mathrm{H}^{*}=\Delta^{\mathrm{L}}\left(\right.$-abit) $\Lambda^{\mathrm{L}} \mathrm{M}^{*} \Phi^{\mathrm{T} * \mathrm{RG} 2 \mathrm{P}} \mathrm{O} \Gamma^{\mathrm{A}}$; adplicuit $\mathrm{H}^{2}=7109146 \mathrm{~V} \|$ 5.7: cum ] $\mathrm{H}^{2}$; com $\mathrm{H}^{*} \|$ <et> ] rest. cum 7109146195210 V et LXX || 5.8: cepit ] coepit $\mathrm{H}|| \mid$ 5.9: congregatae ] congregate $\mathrm{H} \|$ fugierunt ] $\mathrm{H}^{*}=$ $\Sigma^{\mathrm{T}} \Phi^{\mathrm{T} 2} \Theta^{\mathrm{SAM}} \mathrm{Q}^{*}$; fugerunt $\mathrm{H}^{2}=7109146195210 \mathrm{~V} \|$ Dathem ] sic $\mathrm{H}$; $c f .109$ (datema), 7 (dathema), 195 (dathemath), 210 (dathemat), $V$ (datheman), et LXX $(\Delta \alpha \theta \varepsilon \mu \alpha) ; c f$. ABEL «Topographie» pág. $516 \|$ munitionem ] $\mathrm{H}^{2}$; monitionem $\mathrm{H}^{*}$ $=\Delta^{\mathrm{L}} \|$ 5.10: Congregatae ] congregate $\mathrm{H} \| \mid$ 5.12: ueni ] ni in ras. $\mathrm{H}^{2}$; leg. neq. $\mathrm{H}^{*}$

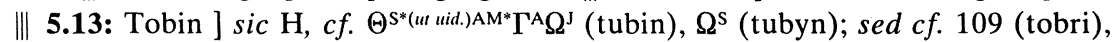
146 (tobi), $V$ (Tubi) et LXX (Toußtov) \| et \{quia\} perdiderunt ] sic $\mathrm{H} ;$ cf. 7109

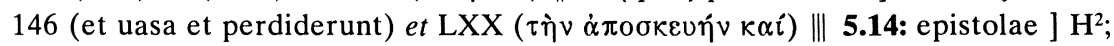
aepistolae $\mathrm{H}^{*} \|$ 5.18: reliquit ] reliquid $\mathrm{H} \| \mid \mathbf{5 . 2 0} \overline{\mathrm{VIII}}$ ] = 'octo milia' $\|$ 
${ }^{21}$ Et abiit Symon in Galileam et commisit proelia multa cum gentibus, et contritae sunt gentes a facie ipsius. ${ }^{22}$ Et persecutus est eos usque ad portam Ptolomaidis, et ceciderunt de gentibus fere tria milia uirorum, et accepit spolia eorum. ${ }^{23} \mathrm{Et}$ sumpsit eos qui erant de Galilea et in Arbatis cum mulieribus et natis et omnia quae erant illis, et duxit in Iudaeam cum laetitia magna. ${ }^{24}$ Et Iudas Machabeus et Ionathas et fratres eius transierunt Iordanen et abierunt uiam trium dierum in desertum, ${ }^{25}$ et occurrerunt eis $\mathrm{Na}$ bathaei, et obuiauerunt eis pacati. Et narrauerunt eis omnia quae acciderant fratribus eorum in Galaditide, ${ }^{26}$ et quia multi ex eis conprehensi sunt in Basara et Bosor, et in Alimis, et Casphon, Maged et Carnaen, hae ciuitates munitae et magnae, ${ }^{27}$ sed et in ceteris ciuitatibus Galaditidis sunt conprehensi; et in crastinum constituerunt admouere ad munitiones et conprehendere et tollere omnes istos in una die. ${ }^{28} \mathrm{Et}$ conuersus est Iudas et exercitus eius uiam in desertum in Bosora repente et occupauit ciuitatem et occidit omnem masculinum in ore gladii et accepit omnia spolia eorum et succendit eam igni. ${ }^{29} \mathrm{Et}$ surrexit inde nocte et ibant usque ad munitionem. ${ }^{30} \mathrm{Et}$ factum est diluculo, leuauerunt oculos suos, et ecce populus multus cuius numerus non erat, portantes scalas et machinas ut comprehenderent munitionem, et expugnabant eos. ${ }^{31} \mathrm{Et}$ uidit Iudas quia coepit bellum, et clamor belli ascendit ad caelum sicut tuba et clamor magnus de ciuitate. ${ }^{32}$ Dixitque uiris exercitus: Pugnate hodie pro fratribus uestris. ${ }^{33} \mathrm{Et}$ exiit tribus ordinibus post eos, et exclamauerunt tubis et clamauerunt in oratione. ${ }^{34} \mathrm{Et}$ cognouerunt

5.22: persecutus ] persequutus $H \| \mid$ 5.23: natis ] ut uid. $H \|$ Iudaeam ] iudeam $H$ || 5.25: Nabathaei ] sic $\mathrm{H}$ cum $\Delta^{\mathrm{L}} \Lambda^{\mathrm{L}} \Theta^{\mathrm{S} 2 \mathrm{AM}} \mathrm{Z}^{2} \Gamma^{\mathrm{A}}$ (nabathei); cf. 7109 (nabateis)

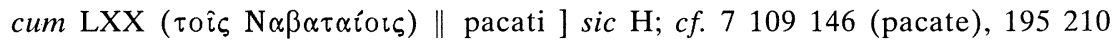

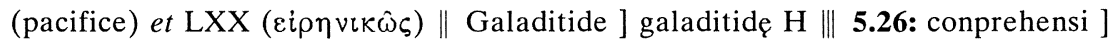
conpraehensi H \| Casphon ] H $=7109195$ 210; sed cf. V (Casfor) cum LXXAsca. 6246106 ( $\kappa \alpha \sigma \phi \omega \rho) ; 146$ (chaspho) et LXX (X $\alpha \sigma \phi \omega) \|$ Maged ] H = 7; cf. 109 (maget), $V$ (Macet) cum LXX (M $\alpha \kappa \varepsilon \delta) \|$ Carnaen ] sic H; cf. 146195210 (carnen), $V$ (Carnain) cum LXX (K $\alpha \rho v \alpha i v)$ ||| 5.27: conprehensi ] conpraehensi H \| conprehendere] conpraehendere $\mathrm{H} \|$ 5.28: Bosora ] sic $\mathrm{H}=67$; $c f .109$ (bosra) et LXX

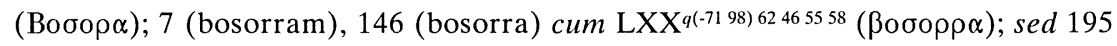

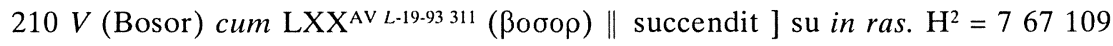
195210 V; leg. neq. $\mathrm{H}^{*}$; cf. 146 (incendit) $\|$ 5.30: diluculo ] $\mathrm{H}^{2}$; dilucolo $\mathrm{H}^{*} \|$ 5.31: de ciuitate ] sic $\mathrm{H}$; probabiliter glossa marginalis apud belli in falsum locum

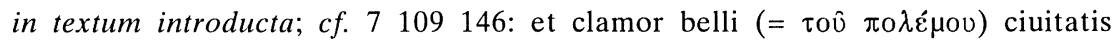
(= $\tau \hat{\eta} \varsigma \pi \delta ́ \lambda \varepsilon \omega \varsigma)$ ascendit in caelum sicut tuba et clamor magnus; $c f$. LXX (ö $\tau$

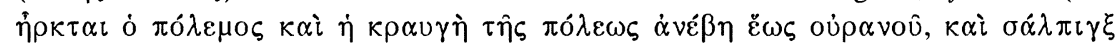
$\kappa \alpha \grave{\imath} \kappa \rho \alpha \cup \gamma \dot{\eta} \mu \varepsilon \gamma \alpha \dot{\alpha} \lambda) \|$ 
castra Timothei quod Macchabeus esset, et fugierunt a facie eius, et percusserunt eos plaga magna, et ceciderunt ex eis in illa die fere octo milia uirorum. ${ }^{35} \mathrm{Et}$ deuertit Iudas in Maspha et conclusit illam in Mella et expugnauit et cepit eam et occidit omne masculinum eius et sumpsit spolia eius et succendit eam igni. ${ }^{36}$ Inde perrexit et cepit Casbon, et Maced, et Bosor et reliquas ciuitates Galaditidis. ${ }^{37}$ Post haec autem uerba congregauit Timotheus exercitum alium et adplicuit ad faciem Raphon trans torrentem. ${ }^{38} \mathrm{Et}$ misit Iudas speculari exercitum, et renuntiauerunt ei dicentes: Conuenerunt ad hos omnes gentes quae in circuitu nostro sunt, et exercitus multus nimis, ${ }^{39}$ et Arabes conduxit in auxilium sibi, et adplicuit trans torrentem, parati uenire ad te in proelium. Et abiit Iudas obuiam illis. ${ }^{40} \mathrm{Et}$ ait Timotheus principibus exercitus sui: Cum adpropriauerit Iudas et exercitus eius ad torrentem aquae, si transierit ad nos prior, non poterimus sustinere eum, quia potens poterit aduersum nos; ${ }^{41}$ si uero adplicuerit et timuerit transire et posuerit castra, transfretemus ad eos et poterimus aduersus illum. ${ }^{42} \mathrm{Ut}$ autem adpropriauit Iudas ad torrentem aquae, statuit scribas populi secus torrentem et mandauit eis dicens: Neminem hominem relinqueritis, sed ueniant omnes in proelium. ${ }^{43} \mathrm{Et}$ transfretauit ad illos prior, et omnis populus post eum, et contritae sunt ante faciem eorum omnes gentes et proiecerunt arma sua et fugierunt in lucum quod est in Carnaim. ${ }^{44} \mathrm{Et}$ occupauerunt ipsam ciuitatem et lucum succenderunt igni cum omnibus qui erant in ipso, et oppressa est Carnaim, et non poterat amplius sustinere contra faciem Iudae. ${ }^{45} \mathrm{Et}$ congregauit Iudas uniuersum Israhel qui erant a Galaditide a minimo usque ad maximum et uxores eorum et natos et uasa et exercitum magnum ualde, ut uenirent in terram Iuda. ${ }^{46} \mathrm{Et}$ uenerunt usque ad Ephron, et haec ciuitas magna, in ingressu posita, munita ualde, et non declinare ab ea dextra uel sinistra, sed per medium eius iter erat. ${ }^{47} \mathrm{Et}$ cluserunt contra eos, qui erant in ciuitate, et oppilauerunt portas lapidibus. ${ }^{48} \mathrm{Et}$ misit ad eos Iudas uerbis pacificis dicens: Transeamus per terram uestram ut eamus in terram nostram, et nemo uobis nocebit, tantum pedibus transibimus. Et nolebant eis aperire.

5.35: Et deuertit ... in Mella ] lectio duplex: et ${ }^{1}$... Maspha cum $V$; et ${ }^{2}$... Mella

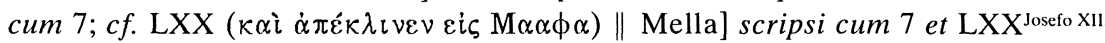
${ }^{340}(\mathrm{M \varepsilon} \lambda \lambda \alpha)$; malum $\mathrm{H} \|$ cepit ] coepit $\mathrm{H} \| \mid$ 5.36: cepit ] coepit $\mathrm{H} \|$ Casbon ] sic

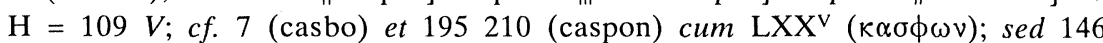
(chaspho) cum LXX (X $\alpha \sigma \phi \omega)|| \mid$ 5.38: misit ] missit $\mathrm{H} \|$ speculari ] $\mathrm{H}^{2}=7109$

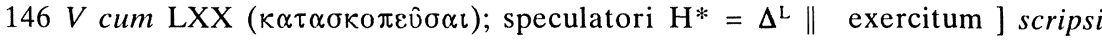

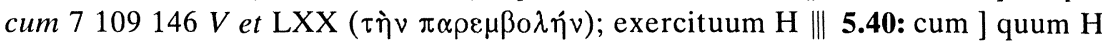
|| 5.42: relinqueritis ] reliqueritis $H||$ 5.43: contritae ] contritę $H$ || 
${ }^{49} \mathrm{Et}$ praecepit Iudas praedicare in castris ut adplicarent unusquisque in quo erant loco. ${ }^{50} \mathrm{Et}$ adplicuerunt uiri uirtutis, et expugnauit ciuitatem illam tota die et tota nocte, et tradita est ciuitas in manu eius. ${ }^{51} \mathrm{Et}$ perdiderunt omnem masculinum in ore gladii, et eradicauit eam et accepit spolia eius et transiit per portam super interfectos. ${ }^{52} \mathrm{Et}$ transgressi sunt Iordanen in campum magnum contra faciem Bethsan. ${ }^{53} \mathrm{Et}$ erat Iudas congregans postremos et exhortabatur populum per totam uiam, donec uenerunt in terram Iuda. ${ }^{54} \mathrm{Et}$ ascenderunt in montem Sion cum laetitia et gaudio, et obtulerunt holocausta, quod nemo ex eis cecidisset donec reuerterentur in pace. ${ }^{55} \mathrm{Et}$ in diebus quibus erat Iudas et Ionathas in terra Galaad, et Symon frater eius in Galilea contra faciem Ptolomaidis, ${ }^{56}$ audiuit Ioseph, Zachariae filius et Azariae, princeps uirtutis, res bene gestas et proelia quae fecerant, ${ }^{57}$ et dixit: Faciamus et ipsi nobis nomen et eamus expugnare ad gentes quae in circuitu nostro sunt. ${ }^{58} \mathrm{Et}$ denuntiauit his qui erant de exercitu eorum, et abierunt ad Iamniam. ${ }^{59} \mathrm{Et}$ exiit Gorgias de ciuitate et uiri eius obuiam illis ad pugnam. ${ }^{60} \mathrm{Et}$ fugatus est Ioseph et Azarias, et fugati sunt usque ad fines Iudae, et ceciderunt in illa die de populo Israhel fere duo milia uiri. ${ }^{61} \mathrm{Et}$ facta est fuga magna in populo, quia non audierunt Iudam nec fratres eius, existimantes se fortiter facturos. ${ }^{62} \mathrm{Ipsi}$ autem non erant de semine uirorum illorum per quorum manus salus data est in Israhel. ${ }^{63} \mathrm{Et}$ uir Iudas et fratres eius magnificati sunt ualde in conspectu omnis Israhel et gentium omnium ubi audiebatur nomen eorum, ${ }^{64} \mathrm{et}$ conuenerunt ad eos bene adclamantes. ${ }^{65} \mathrm{Et}$ exiit Iudas et fratres eius, et expugnabant filios Israhel qui desaeuierant a lege cum filiis Esau in terram quae ad austrum est, et percussit Chebron et filias eius et destruxit munitiones eius et muros eius succendit in circuitu. ${ }^{66} \mathrm{Et}$ mouit castra ut iret in terram alienigenarum et perambulabat Samariam. ${ }^{67}$ In illa die ceciderunt sacerdotes in bello, dum uult fortiter facere, dum sine consilio exiit in proelium. ${ }^{68} \mathrm{Et}$ declinauit Iudas in Azotum terram alienigenarum, et diruit aras eorum, et spolia deorum eorum succendit igni, et spoliauit exuuias ciuitatum, et reuersus est in terram Iuda.

5.51: omnem ] $\mathrm{H}^{*}=767146195210 \mathrm{~V}$; omne $\mathrm{H}^{2}=109 \mathrm{SZ} * \mathrm{O}^{*}$ cum $\mathrm{LXX}(\pi \hat{\alpha} v)$

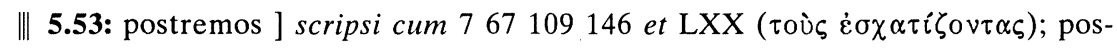
tremo H || 5.56: Azariae ] $\mathrm{H}=7 * 67$ (azarie); sed cf. $109195210 \mathrm{~V}$ (Azarias) cum LXX $(\mathrm{A} \zeta \alpha \rho i \alpha \varsigma) \|||$ 5.60: Iudae ] sic $\mathrm{H}=195210 \mathrm{C} \Sigma \Lambda^{\mathrm{L}} \mathrm{M} \Phi S Z^{2} \mathrm{O} \Psi^{\mathrm{D}} \Omega^{\mathrm{M}}$; sed $c f$.

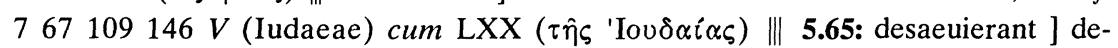
seuierant $\mathrm{H}$; $c f .109$ (desierant) $\|$ 5.68: exuuias ] exubias $\mathrm{H} \|$ 
6.- ${ }^{1}$ Et rex Antiochus perambulabat superiores regiones et audiuit esse ciuitatem Elymaidem in Perside, ciuitatem gloriosam diuitiis argento et auro, ${ }^{2}$ et templum quod in eo locuples ualde, et illic uelamina aurea et loricae et scuta quae reliquit Alexander Philippi rex Macedo qui regnauit primus in Graecis. ${ }^{3}$ Et uenit et quaerebat capere ciuitatem et diripere eam et non potuit, quoniam innotuit sermo his qui erant in ciuitate. ${ }^{4} \mathrm{Et}$ restituerunt eum in proelium et fugiit et abiit inde cum tristitia magna ut rediret in Babyloniam. ${ }^{5}$ Et uenit qui nuntiaret ei in Perside quia fugata sunt castra quae erant in terra Iuda, ${ }^{6}$ et quia abiit Lysias cum uirtute forti in primis et fugatus est a facie Iudaeorum, et praeualuerunt armis et uiribus et spoliis multis quae ceperunt de castris [abominationem] quae exciderunt, ${ }^{7}$ et diruerunt exsecramentum quod aedificauerat super altare quod erat in Hierusalem, et sanctificationem sicut prius circumdederunt muris altis Bethsuram et ciuitates eius. ${ }^{8} \mathrm{Et}$ factum est ut audiuit rex sermones istos, expauit et commotus est ualde, et decidit in lectum et incidit in languorem prae tristitia, quia non est ei factum sicut cogitabat. ${ }^{9} \mathrm{Et}$ erat illic dies multos, quoniam renouata est in eo tristitia magna, et arbitratus est se mori. ${ }^{10} \mathrm{Et}$ uocauit omnes amicos suos, dixitque illis: Recessit somnus ab oculis meis et concidi et corrui corde prae sollicitudine. ${ }^{11} \mathrm{Et}$ dixi in corde meo: Quousque in tribulationem deueni et tempestate magna in qua nunc sum! quia iucundus eram et dilectus in potestate mea, ${ }^{12}$ nunc uero reminiscor malorum quae feci in Hierusalem, unde abstuli spolia omnia argentea et aurea quae erant in ea, et misi auferri inhabitantes Iuda sine causa. ${ }^{13} \mathrm{Et}$ cognoui quia propter haec inuenerunt me mala ista, et ecce pereo tristitia magna in terra aliena. ${ }^{14} \mathrm{Et}$ uocauit Philippum unum de amicis suis et praeposuit eum super uniuersum regnum suum. ${ }^{15} \mathrm{Et}$ dedit ei diadema et stolam suam et anulum, ut educaret Antiochum filium suum et nutriret eum ut regnaret. ${ }^{16} \mathrm{Et}$ mortuus est illic Antiochus rex anno nono et quadragesimo et centesimo.

6.1: Antiochus ] anthiocus $\mathrm{H} \| \mid$ 6.2: reliquit ] reliquid $\mathrm{H} ;+$ illic $\mathrm{H}^{2}=7109$ cum

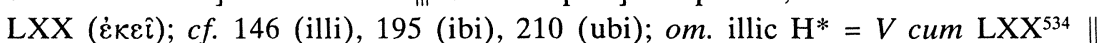
graecis ] graetis $\mathrm{H} \| \mid$ 6.4: eum ] $\mathrm{H}^{*}$; ei $\mathrm{H}^{2}=7109146195210$ cum LXX ( $\left.\alpha \dot{v} \tau \hat{\varphi}\right)$ || 6.5: Perside ] $\mathrm{H}^{*}=109146195210 \mathrm{~V}$; Persiden? $\mathrm{H}^{2}$ || 6.6: Iudaeorum ] iudęorum $\mathrm{H} \|$ ceperunt ] coeperunt $\mathrm{H} \|$ castris ] + br. sp. in ras. $\mathrm{H}^{2}$; leg. neq. $\mathrm{H}^{*} \|$ [abominationem] ] del.; probabiliter glossa marginalis apud exsecramentum (cf. 6.7) in textum introducta, sed in falsum locum || 6.12: quae ] quę $\mathrm{H} \|$ inhabitan-

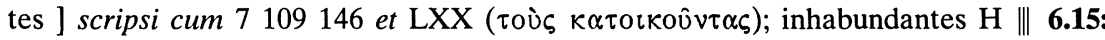
educaret ] edocaret $\mathrm{H} \|$ Antiochum ] anthiocum $\mathrm{H}||$ 6.16: Antiochus ] anthiocus $\mathrm{H} \|$ 
${ }^{17} \mathrm{Et}$ cognouit Lysias quoniam mortuus est rex, et constituit regnare Antiochum filium suum, quem nutriuit adulescentiorem, et uocauit nomen eius Eupater. ${ }^{18} \mathrm{Et}$ qui erant in arce concluserant Israhel in circuitu sanctorum et quaerebant mala semper et firmamentum gentibus. ${ }^{19} \mathrm{Et}$ cogitauit Iudas disperdere eos, et conuocauit uniuersum populum ut obsiderent eos. ${ }^{20} \mathrm{Et}$ coeperunt simul et obsederunt eam anno quinquagesimo et centesimo et fecerunt ballistas et machinas; ${ }^{21}$ et exierunt de conclusis, et adiunxerunt se illis quidam ex impiis Israhel. ${ }^{22} \mathrm{Et}$ abierunt ad regem et dixerunt: Quousque non facies iudicium et uindicabis fratres nostros? ${ }^{23}$ nos destinauimus seruire patri tuo et ambulare in praeceptis eius et sequi dicta eius. ${ }^{24} \mathrm{Et}$ obsederunt filii populi nostri propter hoc et alienabant se a nobis; qui autem inueniebantur ex nobis interficiebantur, et hereditates nostrae diripiebantur. ${ }^{25} \mathrm{Et}$ non ad nos tantum extenderunt manum, sed etiam in omnes fines tuos. ${ }^{26} \mathrm{Et}$ ecce adplicuerunt hodie ad arcem in Hierusalem occupare eam, et munitionem et Bethsuram munierunt; ${ }^{27} \mathrm{et}$ nisi praeuenitis eos uelocius, maiora quam haec facient, et non poteritis obtinere eos. ${ }^{28} \mathrm{Et}$ iratus est rex ut audiuit, et conuocauit omnes amicos suos et principes exercitus sui et eos qui super uehicula; ${ }^{29}$ et de regnis aliis et de insulis et maritimis regionum et uenerunt ad eum exercitus conducticii. ${ }^{30} \mathrm{Et}$ erat numerus exercitus eius $\mathrm{C}$ millia peditum et XX milia equitum et elephanti XXXII scientes proelium. ${ }^{31} \mathrm{Et}$ uenerunt per Idumeam et adplicuerunt ad Bethsuram; et pugnauerunt dies multos et fecerunt machinas; et exierunt et succenderunt eas igni; et pugnauerunt fortiter ${ }^{32}$ et surrexit Iudas de arce et admouit castra ad Bethzachara contra castra regis. ${ }^{33} \mathrm{Et}$ surrexit rex ante lucem et suscitauit exercitum in impetu suo secundum uiam Bethzachara, et conparauerunt se exercitus in proelium et tubis cecinerunt.

6.17: Antiochum ] anthiocum H \| Eupater ] H*; cf. J. PERIN, Onomasticon Totius Latinitatis (Patavii 1913) vol. I pág. 571; cf. 7 (euphator), 67 V SUL chr 2,22,6 (eupator), 109 AN inv 13 (eufator) cum LXX (Eủ $\pi \dot{\alpha} \tau \omega \rho)$; eupatorēm $\mathrm{H}^{2}=146$ $195210 \Pi^{\mathrm{G}} \mathrm{M}^{2} \Theta^{\mathrm{SA}} \Gamma^{\mathrm{A}}$ cum $\mathrm{LXX}^{130} 236$ || 6.19: conuocauit uniuersum ] uit uni leg.

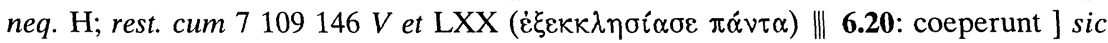
$\mathrm{H}=109$; probabiliter pro coierunt; $c f$. LXX $(\sigma \cup \vee \eta ́ \chi \theta \eta \sigma \alpha \nu) \|$ eam ] + br. sp. in ras. $\mathrm{H}^{2}$; leg. neq. $\mathrm{H}^{*} \|$ machinas] macchinas $\mathrm{H} \|$ 6.26: occupare ] ocupare $\mathrm{H} \|$ 6.29: conducticii ] $\mathrm{H}^{*}=7109$ 146; cf. 195 (conducti) et $\mathrm{LXX}(\mu \tau \sigma \theta \omega \tau \alpha i)$; conducticius $\mathrm{H}^{2}=V \|$ 6.30: millia ] mill $\mathrm{H} \|$ milia ] mil $\mathrm{H} \|$ XXXII ] $\mathrm{H}^{*}=7109146195$

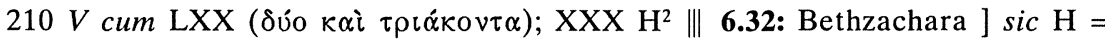
$210^{2} V$ (Bethzachara); cf. 146195 210* (bethzachariam) cum LXX (B $\left.\alpha \imath \theta \zeta \alpha \chi \alpha \rho \imath\right)$ \| contra castra ] in ras. $\mathrm{H}^{2}$; leg. neq. $\mathrm{H}^{*}||$ 
${ }^{34} \mathrm{Et}$ elephantis ostenderunt sanguinem uuae et morae ad instituendos eos in proelium. ${ }^{35} \mathrm{Et}$ diuiserunt bestias in legiones, et adstiterunt singulis elephantis mille uiri loricati cum catenis, et galeae aereae in capitibus eorum, et quingenti equites ordinati singulis bestiis electi. ${ }^{36} \mathrm{Hi}$ ante tempus, ubicumque erat bestia, erant, et quocumque ibat, ibant, non discedebant ab ea. ${ }^{37} \mathrm{Et}$ turres ligneae super eos firmae protectae super singulas bestias, praecincti super eas machinas, et super singulas uiri uirtutis XXXII qui pugnabant super eas et intus eius magister bestiae. ${ }^{38} \mathrm{Et}$ residuum equitatum hinc et inde statuit in duas partes exercitus, commouentes et constipatos in legionibus. ${ }^{39} \mathrm{Et}$ ut effulsit sol in clypeis aureis et aereis, refulserunt montes ab eis et splenduerunt sicut lampades ignis. ${ }^{40} \mathrm{Et}$ extenta est pars exercitus regis super excelsos montes, et alii per loca humilia, et ibant caute et ordinate ...

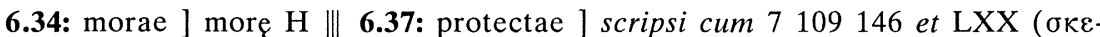
$\pi \alpha \zeta o ́ \mu \varepsilon v o \imath)$; protectis $H$ 


\section{RESUMEN}

Los estudios sobre las antiguas versiones latinas de 1-2 Macabeos han dado a conocer, desde la edición crítica de referencia publicada en 1932 por De Bruyne Sodar, nuevos testimonios de gran utilidad para la reconstrucción de la historia textual de esos libros. Entre ellos destacan los seis primeros capítulos de $1 \mathrm{Maca}$ beos del códice Hubertianus, conservado actualmente en Londres (British $\mathrm{Mu}$ seum, Additional 24142). El texto presenta una gran similitud con otros testimonios conocidos cuya recensión ya estaba en uso en el siglo IV. A pesar de la gran importancia de este testimonio, dado a conocer por B. Fischer en 1965, aún permanece inédito. Con su edición crítica pretendo suplir otra laguna y poner de manifiesto la extraordinaria importancia de dicho testimonio para la historia textual de las antiguas versiones latinas de 1-2 Macabeos y en especial para el conocimiento de la recensión $L$.

\section{SUMMARY}

The Old Latin studies have been enriched with new evidence, very useful for the reconstruction of the textual history of 1-2 Maccabees since the most important critical edition of these books (De Bruyne - Sodar 1932). Among the witnesses included in that edition, the first six chapters of 1 Maccabees in Hubertianus Codex (British Museum, Additional 24142) deserve special attention. Its text is close to other manuscripts that give evidence to a recension current in the 4 th century. $B$. Fisher described this Latin Biblical text in 1965, yet despite its relevance to the textual history, it still remains unedited. With this edition the author shows the importance of this manuscript which fills a gap in the history of the Old Latin text of 1-2 Maccabees, specially for the understanding of $L$ recension. 